\title{
In Situ Creep Model Testing for the Tunnel Anchor Foundation of Xingkang Suspension Bridge in Luding of China
}

\author{
Lina Wen $\mathbb{D}^{1,},{ }^{1,2}$ Qiangong Cheng, ${ }^{1}$ Qiang Cheng, ${ }^{2}$ Xifeng Guo, ${ }^{3}$ and Bin Zhang ${ }^{2}$ \\ ${ }^{1}$ Faculty of Geoscience and Environmental Engineering, Southwest Jiaotong University, Chengdu 610031, China \\ ${ }^{2}$ Sichuan Highway Planning, Survey, Design and Research Institute Ltd., Chengdu 610041, China \\ ${ }^{3}$ Changjiang River Scientific Research Institute, Wuhan 430010, China \\ Correspondence should be addressed to Lina Wen; wln_315410@163.com
}

Received 23 April 2020; Revised 23 July 2020; Accepted 24 August 2020; Published 7 September 2020

Academic Editor: Andreas Lampropoulos

Copyright (C) 2020 Lina Wen et al. This is an open access article distributed under the Creative Commons Attribution License, which permits unrestricted use, distribution, and reproduction in any medium, provided the original work is properly cited.

\begin{abstract}
Due to the limitations of geography and geology, cast concrete tunnel anchors were used to provide counterforces for Xingkang Suspension Bridge foundation at the left bank of Daduhe River. In this study, the in situ creep tests were conducted on two model tunnel anchors at a scale of 1:10 near the real working anchor site. Thus, the long-term deformation of the real working tunnel anchors installed at the bridge foundation could be determined from the creep test of model tunnel anchors. The creep tests were conducted under three different loads and lasted for $102.2 \mathrm{~h}, 167.5 \mathrm{~h}$, and $189.4 \mathrm{~h}$, respectively. The model anchor, the surrounding rock, and their interface were all monitored and measured during the creep testing. In addition, the numerical calculation, in which the Burger creep constitution was used for describing the surrounding rock and the Mohr-Coulomb criterion for describing the concrete anchor, was performed to further evaluate the long-term stability of the real working tunnel anchors. The numerical calculations are in good agreement with the laboratory testing results, and the creep deformations of the anchor and the surrounding rock have the same order of magnitude. The results show that the tunnel anchor and surrounding rock of Xingkang Bridge are in a stable creep state under the three different loads.
\end{abstract}

\section{Introduction}

The Xingkang Bridge, located in Luding County of China, is a key engineering project of the Yakang Expressway connecting Ya'an City and Kangding City. The primary part of this bridge is a large-scale single-span steel truss suspension bridge with a length of $1100 \mathrm{~m}$. Due to the limitations of geography and geology, use of several concrete tunnel anchors was adopted to provide counterforces for the bridge foundation at the left bank of Daduhe River. Compared to the cast concrete gravity anchor often employed in practice of engineering, the concrete tunnel anchor is rarely applied to the foundation of suspension bridge. The tunnel anchor seems to be in the shape of a thermos bottle plug, and it has a short side at the front and a long one at the rear in lengthwise section. Using the geometry of a bottle plug could increase the pullout capacity of an anchor. Thus, the mechanical properties of the rock mass surrounding the anchor could be efficiently used to provide the counterforce needed to guarantee the safety of the bridge foundation.

It is well known that the safety of suspension bridges depends on the stability of bridge foundation to some extent $[1,2]$. In other words, the long-term deformation and stability of tunnel anchor would play a key role in the Xingkang Bridge. Currently, highest attention was paid to the design technology of suspension bridge [3], the reliability analysis of bridge structure $[4,5]$, and the stability evaluation of bridge foundation [6]. However, studies on the tunnel anchor were rarely reported in the limited literature. Han et al. [7] conducted laboratory model tests for the tunnel-type anchorage in soft rock. Zhang et al. [8] carried out numerical calculation of the bridge foundation related to the tunnel anchor. However, the in situ creep model test has not been conducted in the field for the tunnel anchor. Moreover, the long-term deformation of tunnel anchor related to creep would influence the safety running of suspension bridge [9-11]. 
The creep phenomenon and long-term deformation of soft rocks and weak rock mass have been of great concern in practice of engineering since the 1930s. Griggs [12] found that some soft rocks (e.g., claystone, mudstone, and argillaceous slate) would yield creep once the external load reached $12.5-80.0 \%$ of the failure load in laboratory compression tests. Maranini and Brignoli [13] conducted a series of uniaxial and triaxial compression creep tests on limestone samples, observing the propagation of fracture under a low confining pressure and the collapse of pore under a high stress, and pointed out the creep deformation that led to these phenomena. $\mathrm{Li}$ and Xia [14] performed uniaxial compression creep and relaxation tests for four types of rocks (i.e., siltstone, marble, red sandstone, and mudstone) and found that the rock creep characteristics with three variation stages (i.e., first decreasing, then becoming stable, and finally increasing) were similar to each other under a constant stress condition. Tomanovic [15] developed a timedependent creep model for mudstone on the basis of substantial laboratory creep tests, and the creep deformation at any stage could be well described in this model. Chen et al. [16] adopted optimisation techniques to promote the rheological constitutive and got the long-term mechanical parameters of shale. Based on the Burger creep model, Yi et al. [17] gave a scaling criterion under both two- and threedimensional conditions when using rheological parameters, and this criterion demonstrated the rheological behaviour of material under isotropic scaling. In addition, Yang et al. [18] performed several triaxial compression creep tests on the fractured rock masses and proposed a creep damage model, and this model differentiated the creep behaviour of fractured rocks from that of intact rocks.

In this study, the in situ creep tests were performed on the tunnel anchor model at a scale of 1:10 considering the geological conditions at the installation site of the actual tunnel anchor, i.e., Xingkang Bridge foundation near the bank slope at the left bank of Daduhe River. The creep deformations of the tunnel anchor model and the surrounding rocks were collected during testing. Furthermore, we employed the commercially available software FLAC ${ }^{3 \mathrm{D}}$ to calculate the creep deformations based on the Burger creep model. The creep deformation pattern of actual tunnel anchor and its influence on the long-term stability of Xingkang Bridge were analysed in terms of experimental measurements and numerical calculations. These results are helpful to the reinforcement design of the foundation section of Xingkang Bridge in the Yakang Expressway. This bridge, opened in October of 2018, is in good operation up to date.

\section{Engineering Geology}

The design and reinforcement of bridge foundation depend primarily on the engineering geology conditions. The geological investigations show that there exist strong tectonic activity, frequent seismic activities, and high-intensity earthquakes since the late Pleistocene epoch in the region of the engineering project. The natural slope with a height of $400 \mathrm{~m}$ was formed due to the U-shaped bending at the left bank of the Daduhe River near the bridge foundation. The steep slope was covered with significant deposits of 3 to $5 \mathrm{~m}$ depth at the middle and lower positions. The underlaid rocks are primary composed of strongly altered adamellite. The plan view and profile of engineering geology are plotted in Figures 1 and 2, respectively. Around the bridge site, we have not found any large-scale landslide, and only a few smallscale soil landslides happened about $1 \mathrm{~km}$ away.

The in situ model tunnel anchors are located at approximately $100 \mathrm{~m}$ below the real working anchors of Xingkang Bridge foundation (Figure 3). The surrounding rocks of the tunnels excavated for the model anchors and the real working anchor are both composed of altered adamellite with a similar structure (Figure 4). In the model tunnel, three altered granite walls exist in the adamellite, and no groundwater activity was found. The surrounding rocks are relatively soft and prone to fracture and in medium-tostrong weathered state. Despite no fault, three groups of rock joints $\left(33^{\circ} \angle 72^{\circ}, 57^{\circ} \angle 36^{\circ}\right.$, and $\left.312^{\circ} \angle 67^{\circ}\right)$ exist from the exposed rocks on the tunnel surface of the model anchor. The joint widths are approximately $0.2-0.3 \mathrm{~m}$, with most of them closed and a few slightly opened. When soaking the rocks in water, nail scratches could be easily made on the surface of rock. In addition, we collected the boring rock samples to perform physical and mechanical property tests in the laboratory and carried out sonic velocity measures in the boring holes. The testing results are given in Table 1 . Among the parameters, $\rho_{n}$ is the density, $E$ is the elastic modulus, $\sigma_{c}$ is the compression strength, $\sigma_{t}$ is the tension strength, $\mu$ is the Poisson ratio, $c$ is the cohesion, $\varphi$ is the friction angle, and $w$ is the water content.

\section{In Situ Creep Test of the Tunnel Anchor Model}

In order to determine the creep characteristics of the tunnel anchor and the surrounding rocks, the in site creep tests of two model anchors were conducted. The creep tests comply with the similarity theory in physics. The gas-liquid hydraulic loading system was used for the creep testing method, and grating displacement sensors and dislocation meters were employed to monitor the creep deformation.

3.1. Model Preparation. In order to avoid the influence of model tunnel anchor on the real working tunnel anchor in the process of the creep tests, the two model anchors were placed under the real anchors. Their height difference is approximately $100 \mathrm{~m}$. The location relation between the model anchor and the real one is plotted in Figure 3.

The creep test of tunnel anchor model complies with the similarity theory in physics. The main parameters (strength, load, geometry, and elastic modulus) of the model anchor are determined from (1)-(4) referring to the paper by Lei et al. [19]:

$$
R_{m}=R_{p}
$$

where $R_{m}$ and $R_{p}$ are the strengths of model tunnel anchor and real working anchor, respectively: 


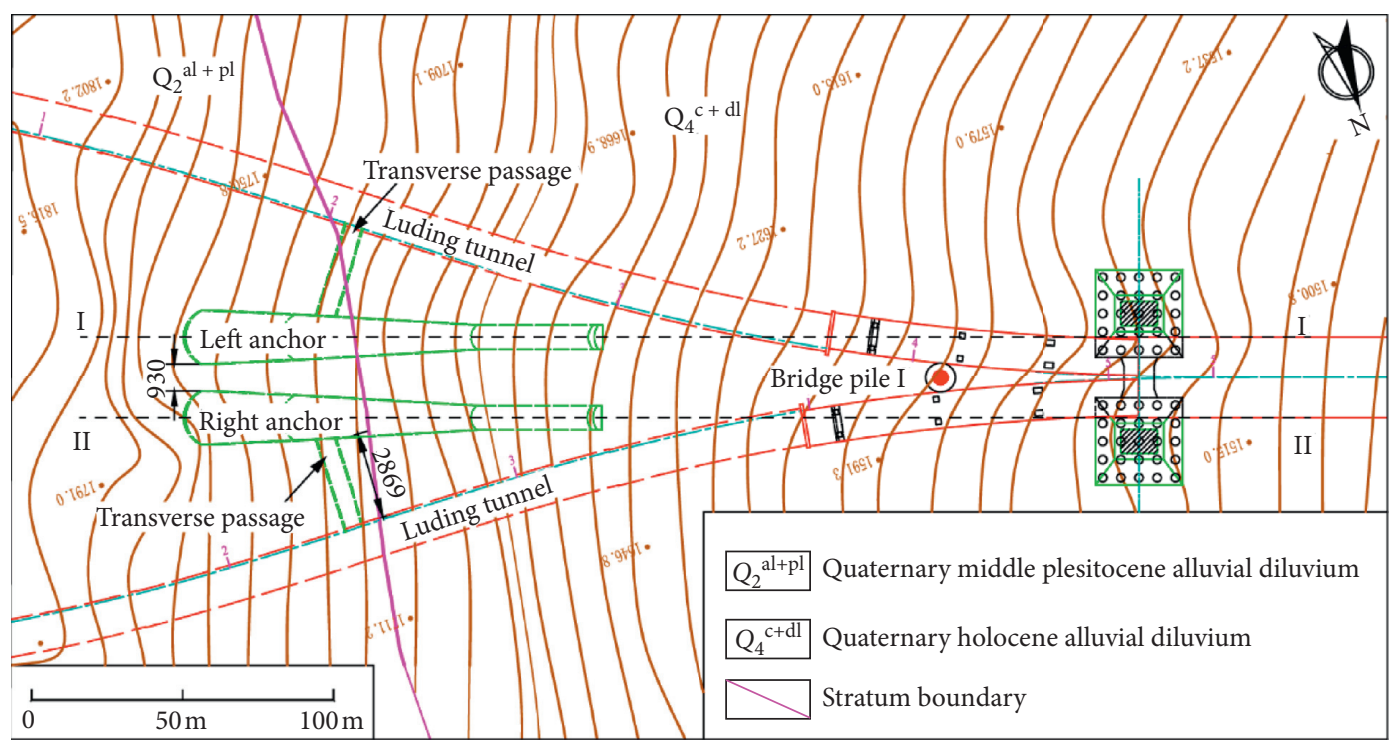

FIGURE 1: Geography and geology near the tunnel anchor site of the Xingkang Bridge.

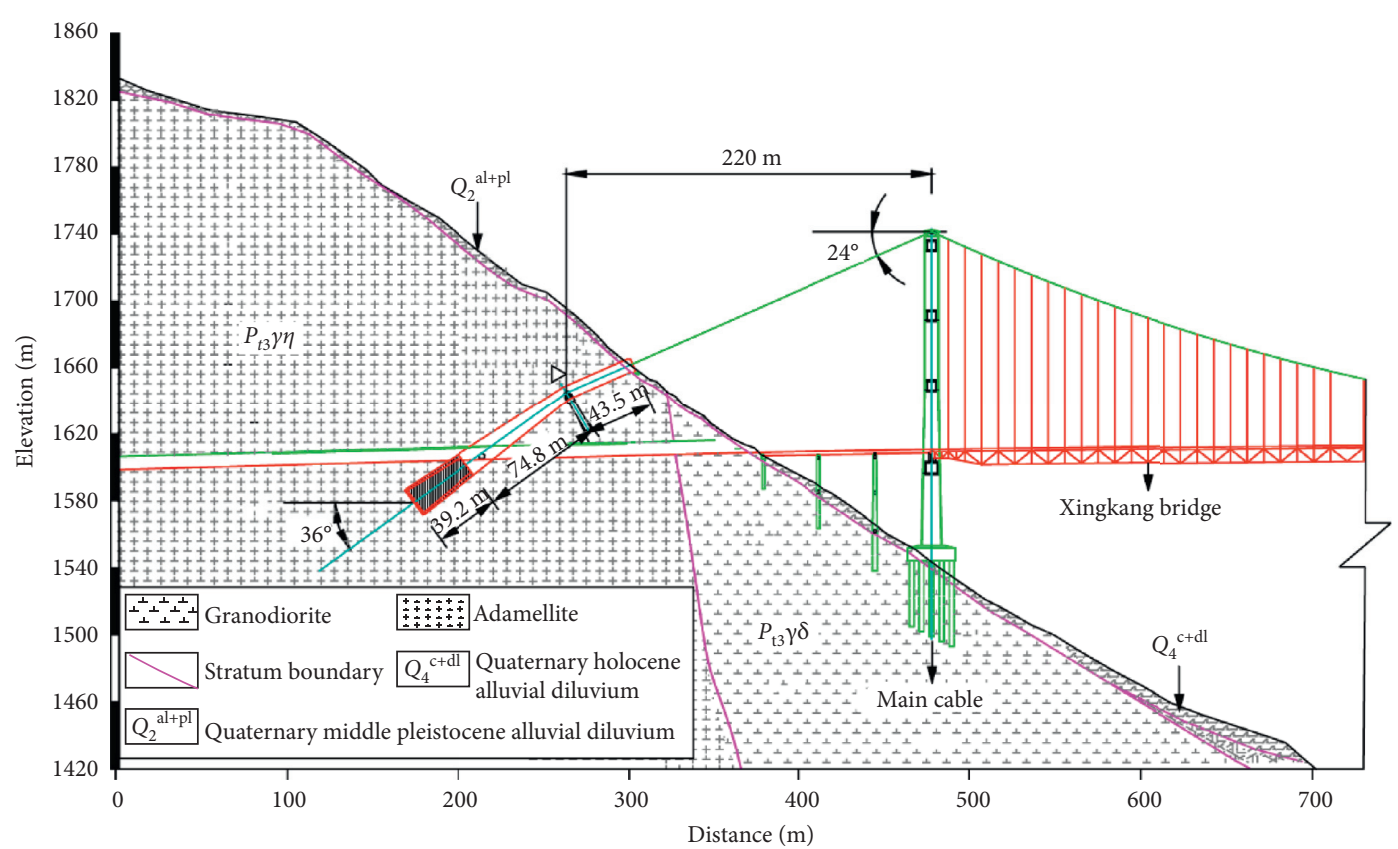

FIgURE 2: Engineering geology profile at the I-I position of Figure 1.

$$
N_{m}=\left(\frac{N_{p}}{C^{2}}\right) \text {, }
$$

where $N_{m}$ and $N_{p}$ are the loads applied on model tunnel anchor and real working anchor, respectively; $C$ is a similarity constant, and the $C$-value is taken to be 10 in this study:

$$
l_{m}=\left(\frac{l_{p}}{C}\right),
$$

where $l_{m}$ and $l_{p}$ are the geometric sizes of model tunnel anchor and real working anchor:

$$
E_{m}=E_{p}
$$

where $E_{m}$ and $E_{p}$ are the elastic moduli of model tunnel anchor and real working anchor, respectively.

The tunnels for model anchor and real working anchor share exactly the same shape and axis direction $\left(115^{\circ} \angle 36^{\circ}\right)$. The top and bottom of model anchor tunnels in cross section are both designed as arc shapes while the side walls are vertical. The two tunnels of model anchors (see Figure 5), used for performing the in situ creep test, were excavated $2.70 \mathrm{~m}$ away from each other (axial distance). The cross sections at the front and rear side of the model tunnel anchor are plotted in Figure 6. The geometry size of front face is $1.48 \mathrm{~m} \times 1.56 \mathrm{~m}$, and that of rear 


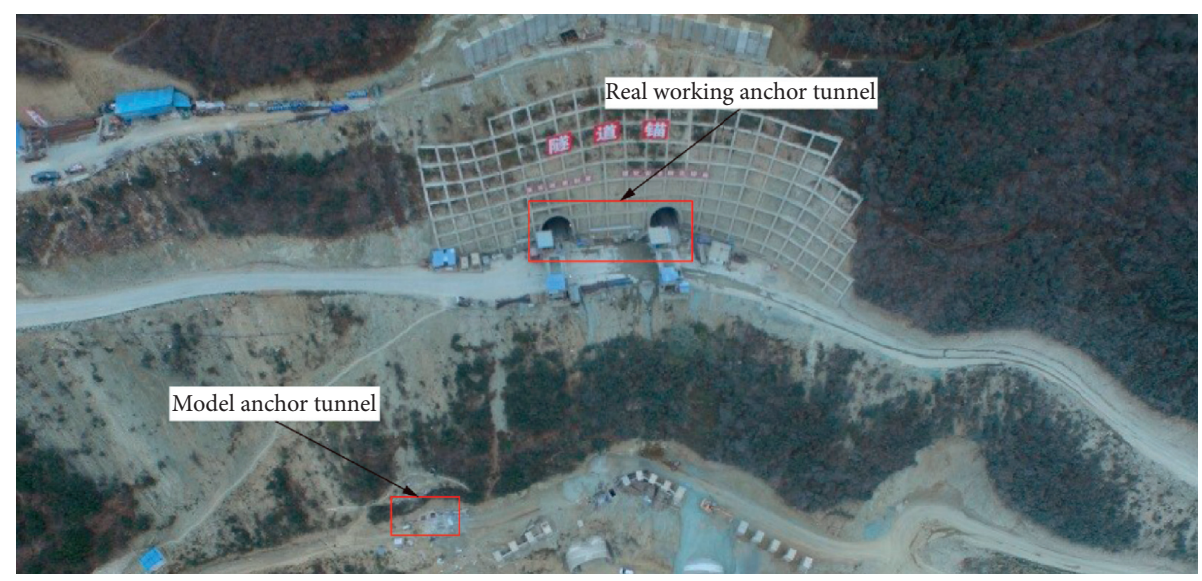

FIGURE 3: Locations of model anchor and real working anchor tunnels.
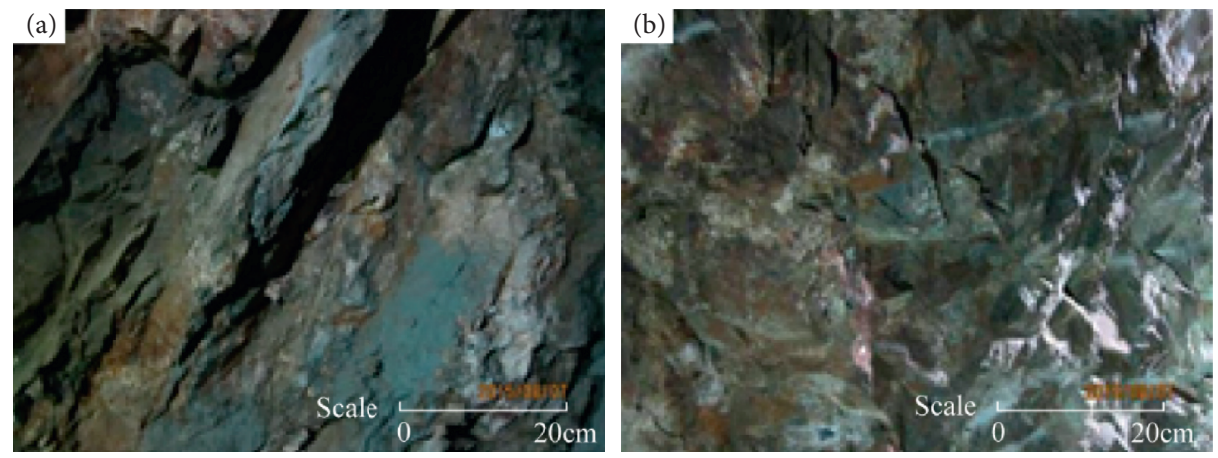

FIGURE 4: Surrounding rocks around (a) real working anchor tunnel and (b) model anchor tunnel.

TABle 1: Physical and mechanical parameters of rock samples.

\begin{tabular}{lcccccccc}
\hline Parameter & $\rho_{n}\left(\mathrm{~g} / \mathrm{cm}^{3}\right)$ & $E(\mathrm{GPa})$ & $\sigma_{c}(\mathrm{MPa})$ & $\sigma_{t}(\mathrm{MPa})$ & $\mu$ & $C(\mathrm{MPa})$ & $\tan \varphi$ & $W(\%)$ \\
\hline Range & $2.54 \sim 2.68$ & $1.06 \sim 5.39$ & $22.4 \sim 46.7$ & $2.5 \sim 3.9$ & $0.26 \sim 0.31$ & $0.6 \sim 1.2$ & $0.71 \sim 0.92$ & $1.07 \sim 1.82$ \\
Average & 2.57 & 2.13 & 32.25 & 3.20 & 0.28 & 0.82 & 0.78 & 1.38 \\
Standard deviation & 0.06 & 1.84 & 8.96 & 0.58 & 0.02 & 0.23 & 0.09 & 0.31 \\
\hline
\end{tabular}

face is $1.77 \mathrm{~m} \times 1.90 \mathrm{~m}$. The length of the model tunnel anchor is $4.00 \mathrm{~m}$. The radii of the arc at the top and bottom of front section are $R_{\mathrm{f} 1}=0.74 \mathrm{~m}$ and $R_{\mathrm{f} 2}=0.92 \mathrm{~m}$, and those of rear section are $R_{r 1}=0.89 \mathrm{~m}$ and $R_{r 2}=1.24 \mathrm{~m}$. The lengths of front and rear anchor chambers are $6.30 \mathrm{~m}$ and $0.60 \mathrm{~m}$, respectively.

3.2. Creep Testing Method. The gas-liquid hydraulic loading system, used for the creep testing method, was made by Jinan Saisite Equipment Co., Ltd. This loading system could offer a high loading capacity, a high-pressure servo control accuracy, and a convenient control function. The detailed configuration of the loading system is shown in Figure 7. The test data were collected automatically through the pressure sensor and data acquisition systems during the loadingunloading process.

According to the design requirement, a single main cable should bear a tension of $N_{p}=2.67 \times 10^{5} \mathrm{kN}$ under the real working condition. Therefore, the design tension of a single cable in the model is transformed to $N_{m}=2.67 \times 10^{3} \mathrm{kN}$ on the basis of (2). After the anchor hole was excavated, 20 jacks were subsequently installed in the rear anchor chamber. To ensure that the model anchor can reach the ultimate failure condition, 10 jacks $\left(3 \times 10^{3} \mathrm{kN}\right.$ per jack) were used to provide the load on a single anchor. By connecting the oil circuit to multiple cylinders and integrating all the jacks in parallel, a maximum load is 11.0 times the design load in the test, e.g., $11.0 \mathrm{~N}_{m}$. The control of load abided by the subsequent load steps of $1.0 N_{m}, 3.5 N_{m}, 7.0 N_{m}, 9.0 N_{m}$, and $11.0 N_{m}$ in the long-term cyclic loading tests and corresponding creep tests for the model anchor. In fact, the surrounding rock around the rear anchor chamber has been locally damaged when the load reached $7.8 \mathrm{~N}_{m}$. In addition, we could judge that the rear section has also reached its ultimate bearing capacity from the observed significant deformation. Thus, the maximum effective load could be taken as $7.0 \mathrm{~N}_{m}$. The creep test lasted for $102.2 \mathrm{~h}, 167.5 \mathrm{~h}$, and $189.4 \mathrm{~h}$ under the loads of $1.0 N_{m}, 3.5 N_{m}$, and $7.0 N_{m}$, respectively. The creep test under each loading condition was terminated when the fluctuation of deformation was within $\pm 3 \mu \mathrm{m}$. 

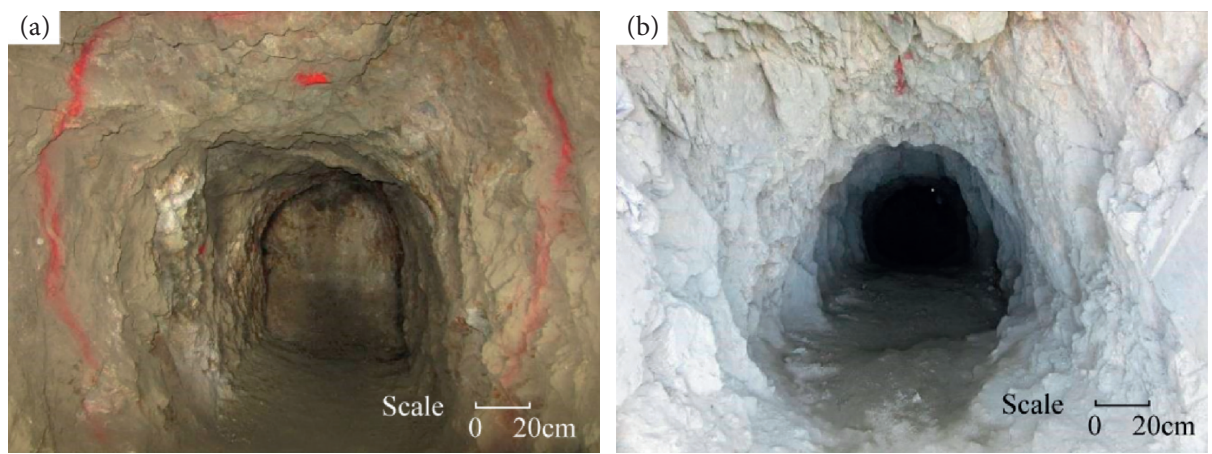

Figure 5: (a) Left tunnel and (b) right tunnel of model anchors.

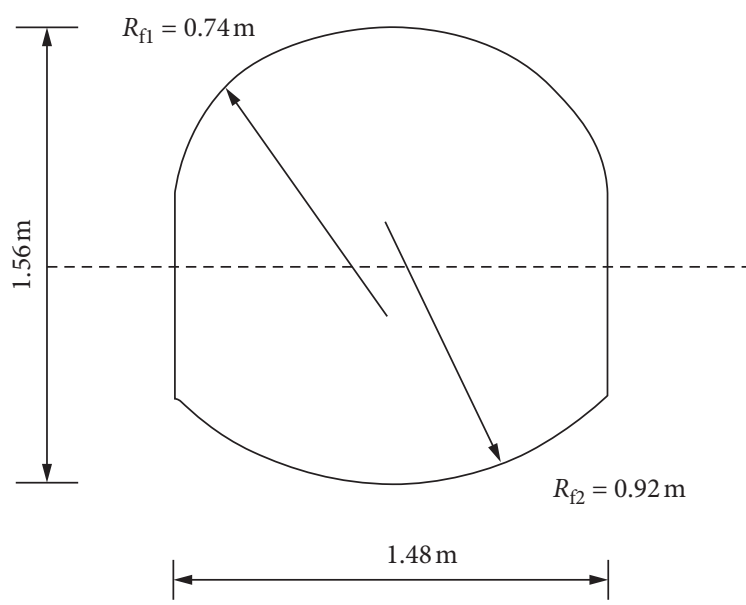

(a)
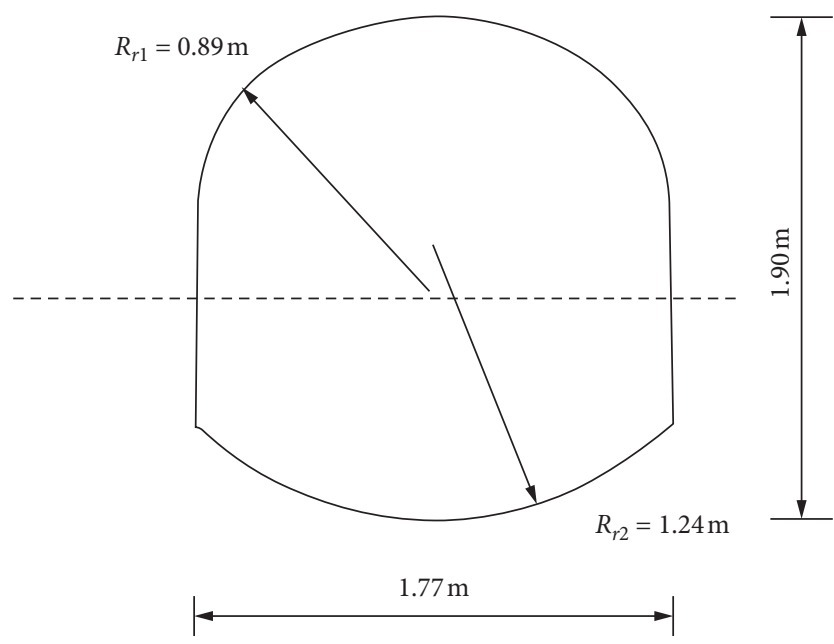

(b)

Figure 6: (a) Front-side surface and (b) rear-side surface of a single model anchor.
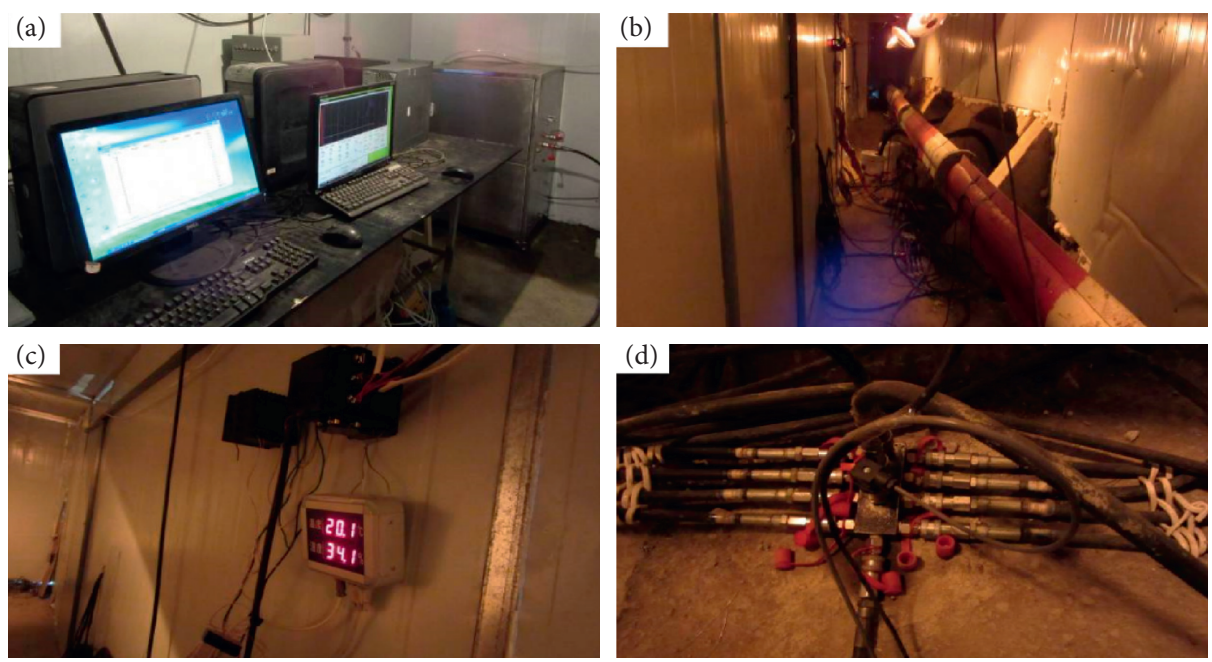

Figure 7: (a) Loading system: data acquisition system, (b) site datum beam of model anchor, (c) temperature monitoring system, and (d) jack oil system of field loading system.

After completing the tests at the three loading stages of $1.0 \mathrm{~N}_{m}, 3.5 \mathrm{~N}_{m}$, and $7.0 \mathrm{~N}_{m}$, the instrument was given a rest for 12 to $24 \mathrm{~h}$ before conducting the corresponding creep test. During the creep test, the creep test results of the anchor and the surrounding rock were analysed by monitoring their long-term deformations. The creep test data were collected every $10 \mathrm{~min}$. The loading process lasted for at least 5 days, and the test was terminated 


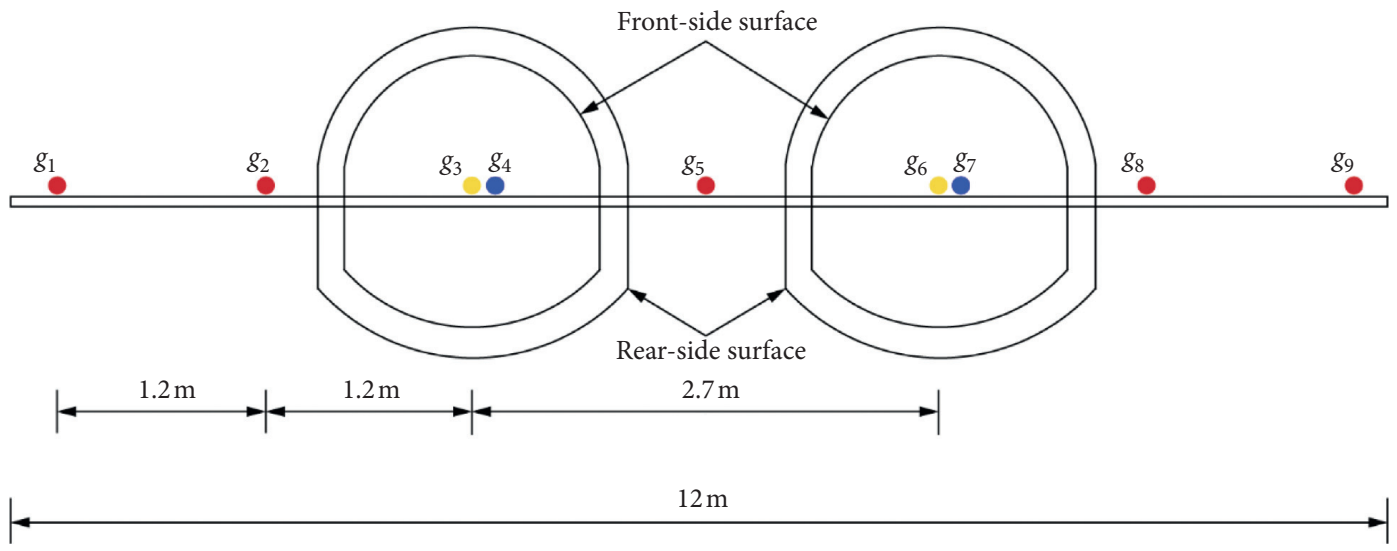

Measuring point position

- Surrounding rock surface

- Front anchor surface

- Rear anchor surface

FIgURE 8: Positions of grating displacement sensors.

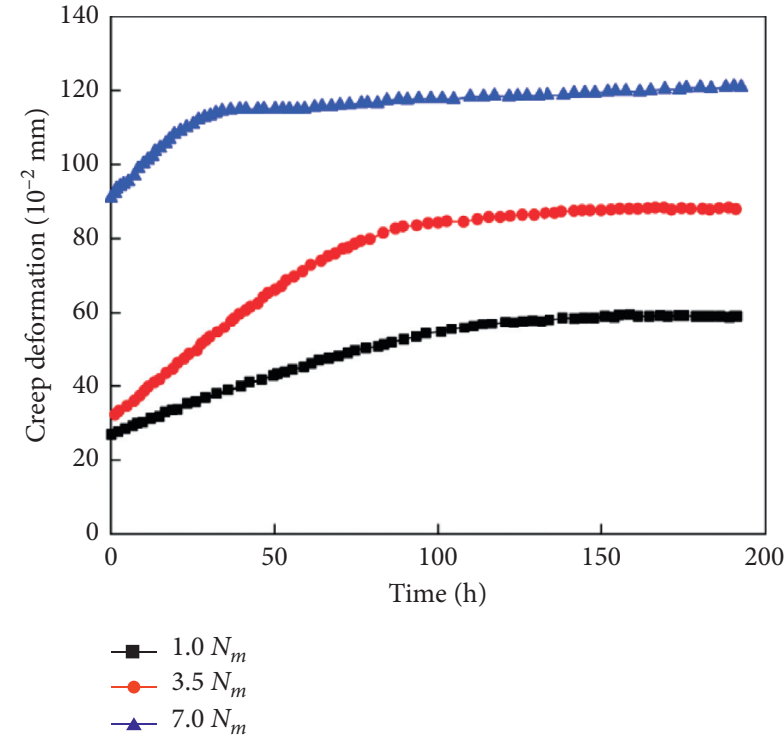

(a)

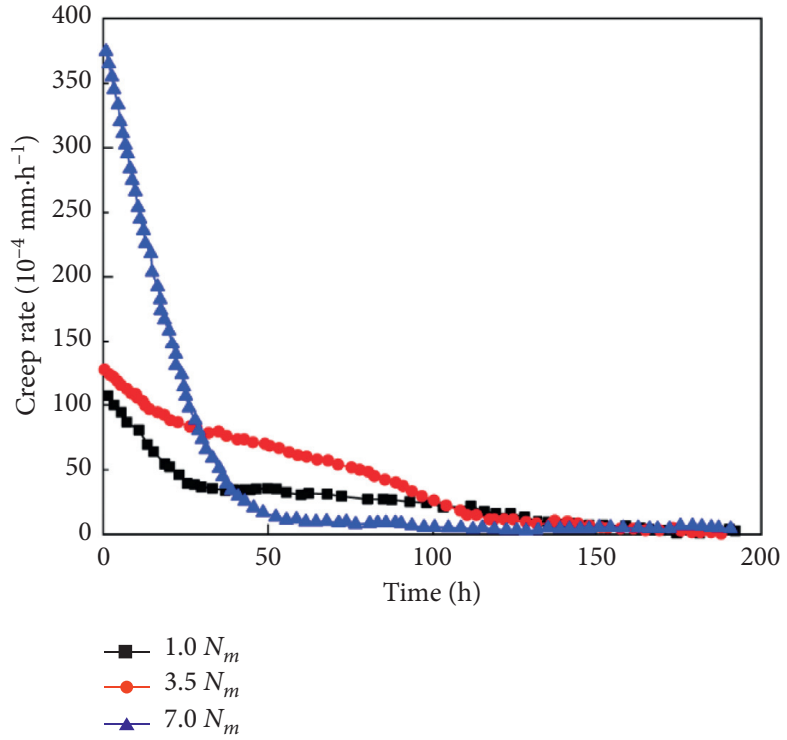

(b)

Figure 9: (a) Deformation and (b) rate of point $g_{7}$ measured during creep testing.

when the deformation was stable (approximately fluctuation within $\pm 3 \mu \mathrm{m})$.

\subsection{Creep Test Results and Analysis}

3.3.1. Monitoring Point Position on the Tunnel Anchor. Grating displacement sensors were used to monitor the creep deformation of the model anchor during the test. Nine sensors were installed on the front anchor face, rear anchor face, and front rock mass along the tensile direction. A long steel beam with length of $12 \mathrm{~m}$ was used as a reference beam. The layout of the grating displacement sensors is plotted in Figure 8. Four measuring points, i.e., $g_{3}$ (located at the front face of the left anchor), $g_{4}$ (located at the rear face of the left anchor), $g_{6}$ (located at the front face of the right anchor), and $g_{7}$ (located at the rear face of the right anchor), were used in the creep test on the anchor.

\subsubsection{Creep Behaviour of the Anchor under Different Loading} Stages. The creep deformations at the front and rear faces of the left and right anchors were measured by the grating displacement sensors under loads of $1.0 \mathrm{~N}_{m}, 3.5 \mathrm{~N}_{m}$, and $7.0 N_{m}$. The stress of measuring point $g_{7}$ was the maximum among all measuring points and the creep deformation was measured at this point every $24 \mathrm{~h}$. The creep deformation and creep rate measured at point $g_{7}$ under different loading conditions were analysed, as presented in Figure 9. 


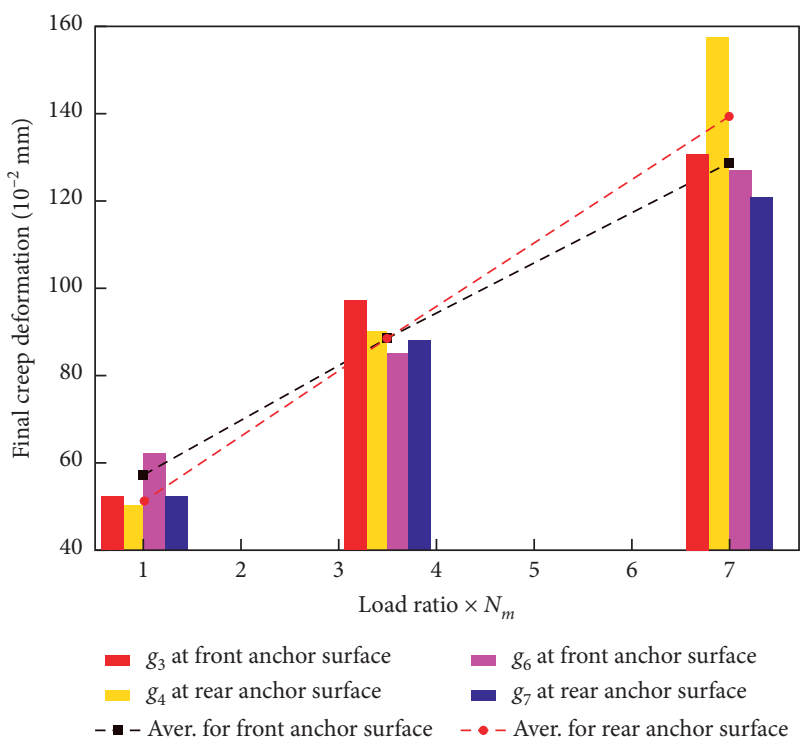

Figure 10: Comparison of creep deformations between two model anchors.

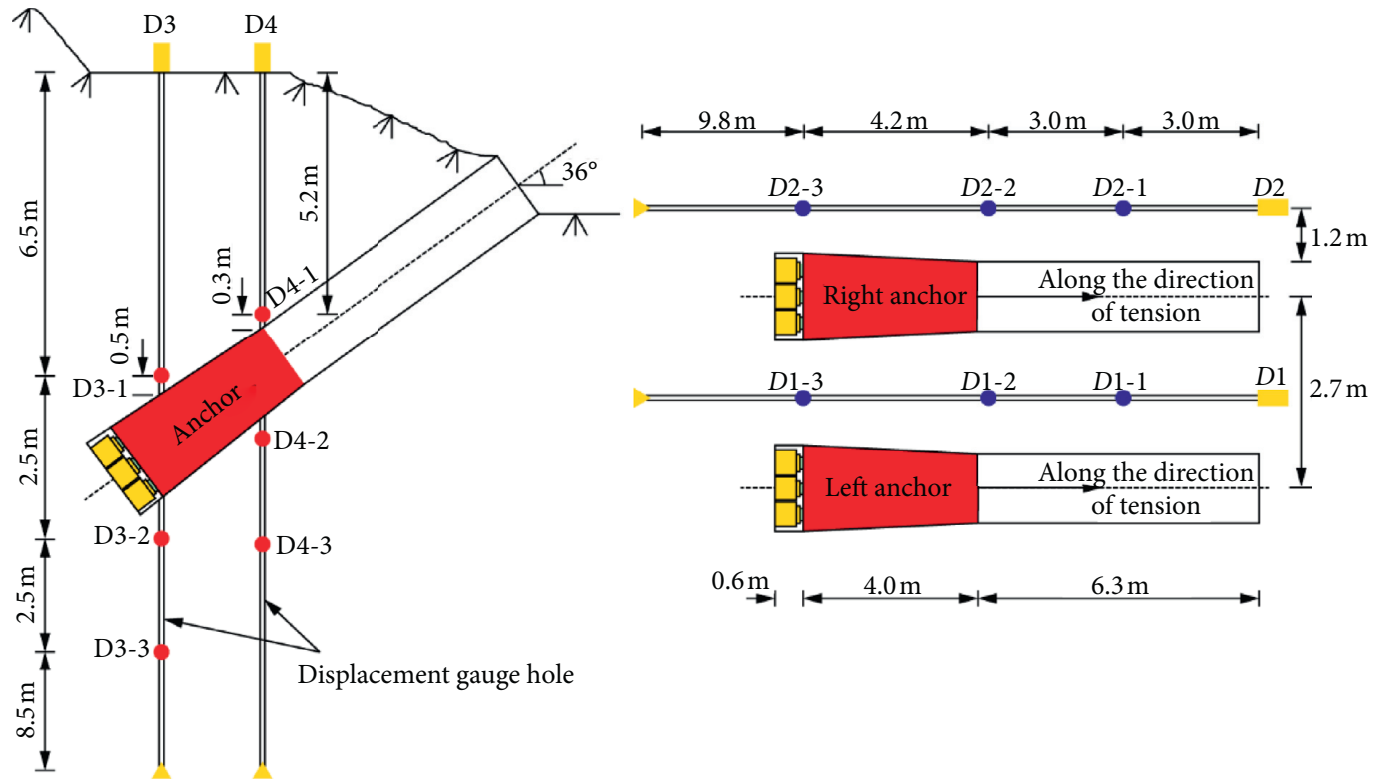

- Multipoint extensometer along the vertical direction

- Multipoint extensometer along the pull direction

- Datum point

FIgURE 11: Multipoint displacement transducers along the (a) vertical direction and (b) tensile direction.

As can be observed from Figure 9, the instantaneous deformation is smaller than the creep deformation under a load of $1.0 N_{m}$. When the load is increased to $3.5 N_{m}$ and $7.0 N_{m}$, however, the instantaneous deformation becomes significantly larger and the fraction of creep deformation becomes smaller in the total deformation. With increasing loading level, the duration of elastic creep experienced by the anchor becomes smaller while the creep deformation and the change in creep rate both become larger.
3.3.3. Influence of the Location of Model Anchor Hole on the Creep Behaviour. The two model anchor tunnels excavated for the model anchors are separated by $2.70 \mathrm{~m}$ in the in situ test, as indicated in Figure 8. The creep deformations measured at points $g_{3}, g_{4}, g_{5}$, and $g_{7}$ are illustrated in Figure 10 .

As shown in the figure, both the left and the right anchors show similar values of creep deformations at all loading conditions. With the same loading level, there is only a subtle difference between the creep deformations measured at 


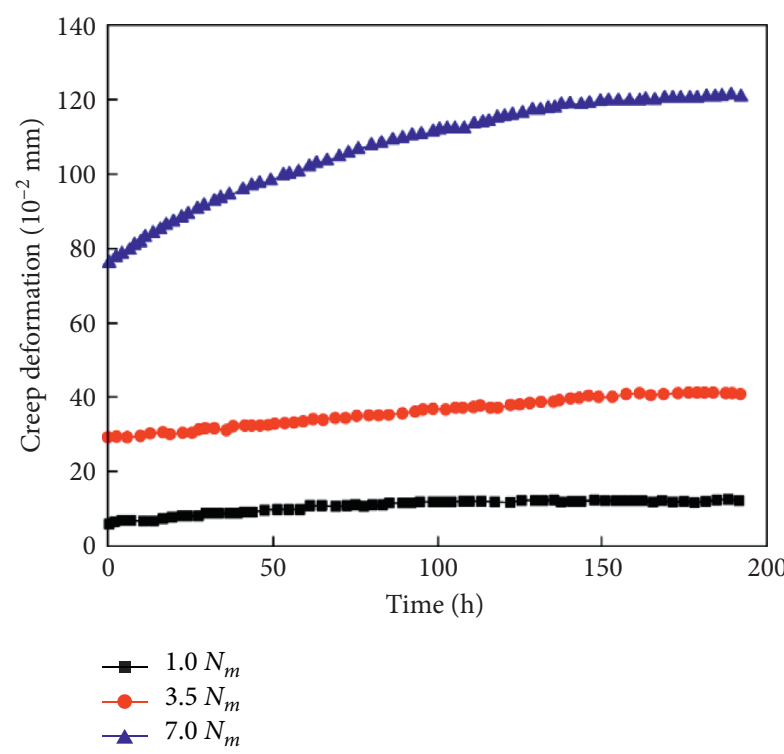

(a)

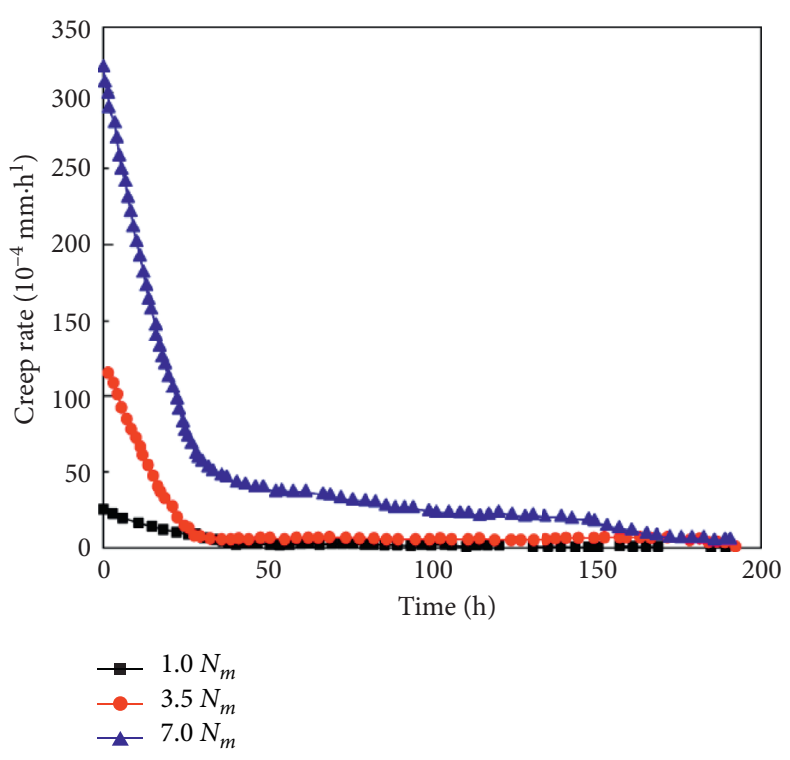

(b)

Figure 12: (a) Deformation and (b) rate of points D1-3 measured during creep testing.

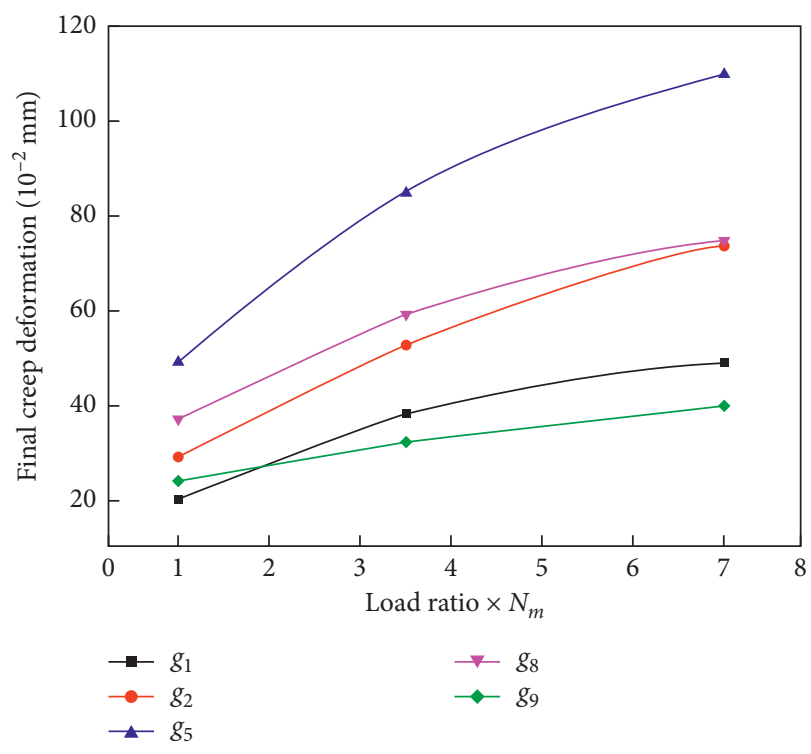

FIGURE 13: Final creep deformation of points $g_{1}, g_{2}, g_{5}, g_{8}$, and $g_{9}$.

different points. Meanwhile, the creep deformations measured at the front and rear faces of the model anchor are almost consistent with each other. The average values of creep deformations measured at $g_{3}$ and $g_{4}$ are $0.51 \mathrm{~mm}, 0.94 \mathrm{~mm}$, and $1.45 \mathrm{~mm}$, respectively, under loads of $1.0 \mathrm{~N}_{\mathrm{m}}, 3.5 \mathrm{~N}_{\mathrm{m}}$, and $7.0 N_{\mathrm{m}}$. The average values of creep deformations measured at $g_{6}$ and $g_{7}$ are $0.57 \mathrm{~mm}, 0.87 \mathrm{~mm}$, and $1.24 \mathrm{~mm}$, respectively, under the three loading conditions.

3.3.4. Monitoring Point Position on the Surrounding Rock. The creep behaviour at the surface of the surrounding rock was tested using grating displacement sensors at five measuring points, namely, $g_{1}, g_{2}, g_{5}, g_{8}$, and $g_{9}$. The layout of these measuring points is also illustrated in Figure 8. The creep behaviour of the inside of the surrounding rock was tested using multipoint vibrating wire displacement transducers. Four measuring holes were drilled inside the rock, and the drilling holes have a diameter of $76 \mathrm{~mm}$. The two drilling holes of D1 and D2 were arranged along the tensile direction. The other two drilling holes of D3 and D4 were arranged along the vertical direction towards the ground surface. The layouts of these drilling holes are plotted in Figure 11.

The creep deformations on the surface and inside of the surrounding rock were tested under loads of $1.0 \mathrm{~N}_{m}, 3.5 \mathrm{~N}_{m}$, and $7.0 N_{m}$. The statistics were conducted from the collected creep deformation data of points D1-3 (the locations of the maximum stress) every $24 \mathrm{~h}$. Figure 12 shows the creep deformation and creep rate measured at these points under the different loading conditions. Figures 13 and 14 indicate the creep deformations on the surface and inside of the surrounding rock.

As shown in Figure 12, the overall range of creep deformation is relatively small for the surrounding rock under the loads of $1.0 \mathrm{~N}_{m}$ and $3.5 \mathrm{~N}_{m}$. However, the creep range becomes relatively large when the load is increased to $7.0 \mathrm{~N}_{m}$. The creep deformation of the surrounding rock is found to increase with increasing load. In addition, a higher load leads to a larger initial creep rate of the surrounding rock as well as a more significant change in the creep rate.

It could be seen from Figure 13 that the maximum creep deformations measured at point $g_{5}$ (located along the tensile direction in the rock mass between the anchors) are $0.49 \mathrm{~mm}, 0.85 \mathrm{~mm}$, and $1.10 \mathrm{~mm}$, respectively, under loads of $1.0 N_{m}, 3.5 N_{m}$, and $7.0 N_{m}$. The creep deformation of the surface surrounding rock measured at other locations along the tensile direction tends to decrease with increasing distance from model anchor. In other words, the creep deformation becomes larger as it gets closer to the anchor. 


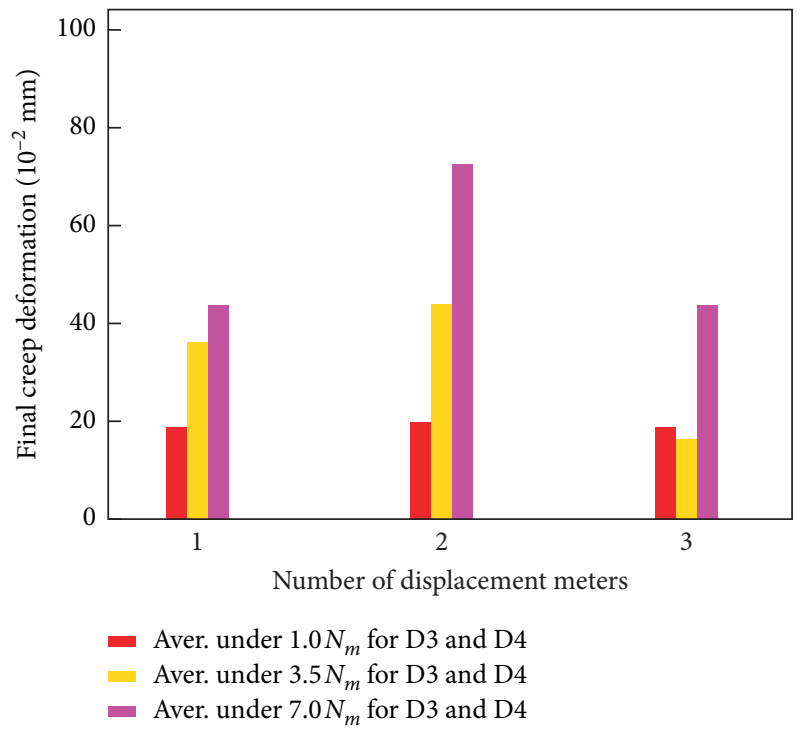

(a)

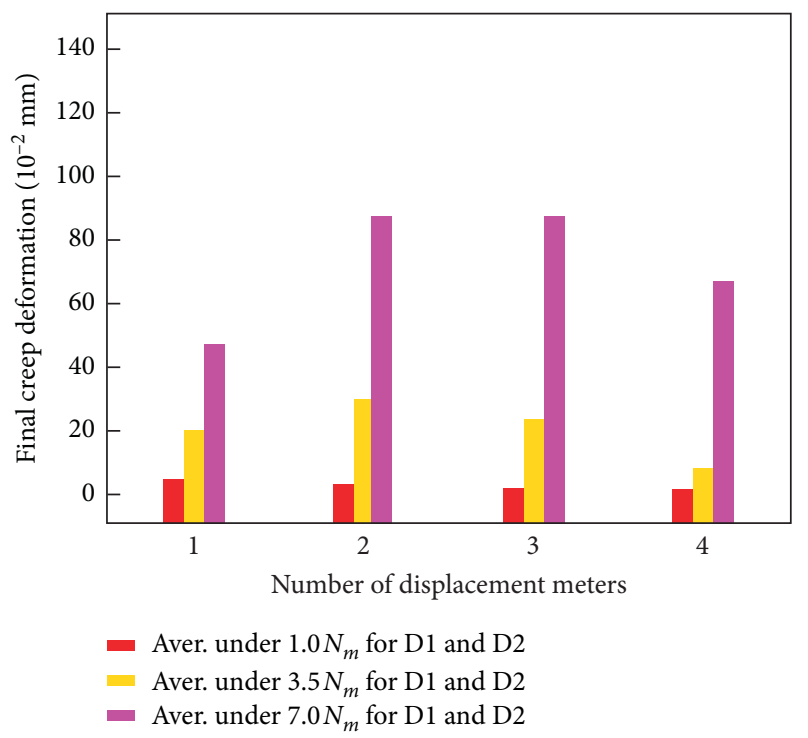

(b)

FIGURE 14: Final creep deformation along the (a) tensile direction and (b) vertical direction in the surrounding rocks.

Figure 14 shows that the creep deformation of the surrounding rock continues to increase with increasing load along both the tensile and vertical directions. In particular, the creep deformation along the vertical direction is larger than that along the tensile direction under the loads of $1.0 N_{m}$ and $3.5 N_{m}$. When the load is increased to $7.0 N_{m}$, however, the creep deformation along the tensile direction becomes slightly larger than that along the vertical direction.

In summary, both the creep deformation and the creep rate of the surrounding rock tend to increase with increasing load level. Meanwhile, due to the sandwiching effect from the two anchors on the left and right sides, the creep deformation at the surface of the surrounding rock tends to become smaller with increasing distance from the anchor. In contrast, the creep deformation becomes larger as it gets closer to the anchor.

3.3.5. On the Interface between Tunnel Anchor and Surrounding Rock. To analyse the creep characteristics of the interface between model tunnel anchor and surrounding rock, six dislocation meters were installed between each model anchor and its contact surfaces with the surrounding rock. Specifically, these meters were arranged on three separate cross sections located at the top arc, bottom plate, and side wall of anchor. Figure 15 displays the detailed layout of the dislocation meters.

The creep deformations of the interface between anchor and surrounding rock were tested under loads of $1.0 \mathrm{~N}_{m}$, $3.5 N_{m}$, and $7.0 N_{m}$. The creep deformation statistics were collected from measuring point WCJ6 (the location with the maximum stress between the anchor and the surrounding rock) every $24 \mathrm{~h}$. The creep deformation and creep rate measured at point WCJ6 under the different loading conditions were then analysed (Figure 16). The creep
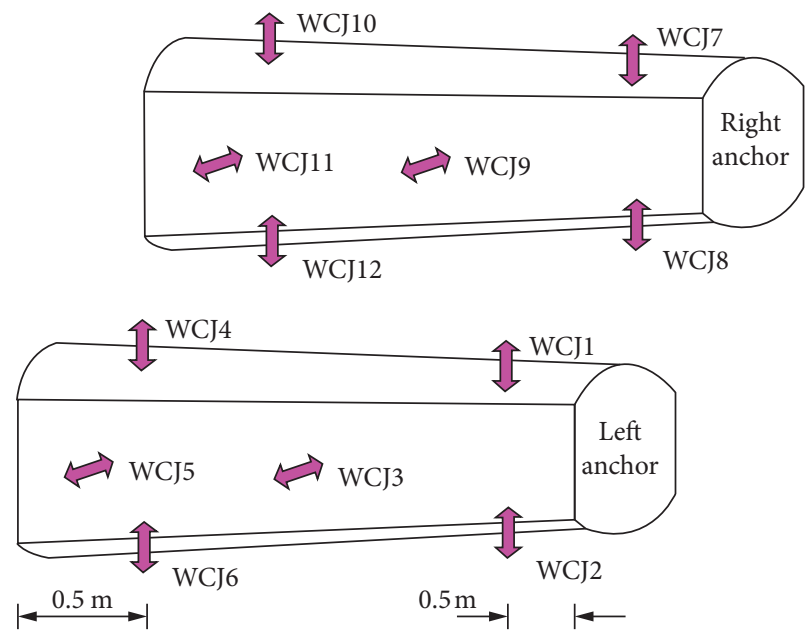

FiguRE 15: Dislocation meters around the two model anchors.

deformations measured at other locations under the different loading conditions are plotted in Figure 17.

As shown in Figure 16, a similar pattern is found for the creep deformation of the anchor, the surrounding rock, and the interface. However, the change in the creep deformation of the interface with increasing load level is slower than that of the anchor and the surrounding rock. In addition, the dislocation experiences a longer elastic period. These findings demonstrate a strong clamping effect from the anchors and surrounding rocks.

As indicated in Figure 17, the creep deformation of the dislocation tends to increase with increasing load level at all measuring points. Under a load of $1.0 N_{m}$, the creep deformations of the dislocation measured at different points are relatively close to each other. When the load is increased to $3.5 N_{m}$, there is already a significant difference between the creep deformations of the dislocation measured at 


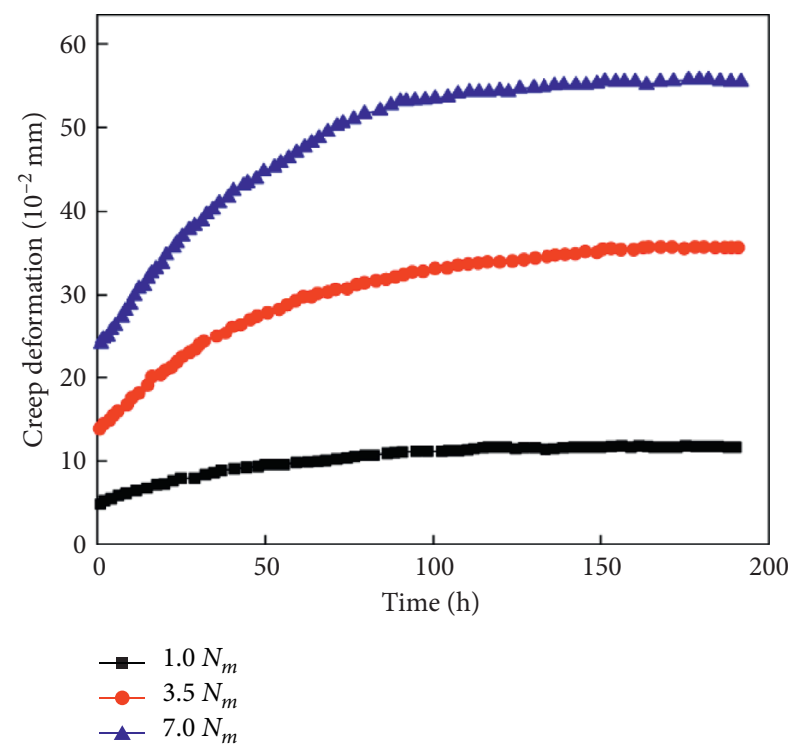

(a)

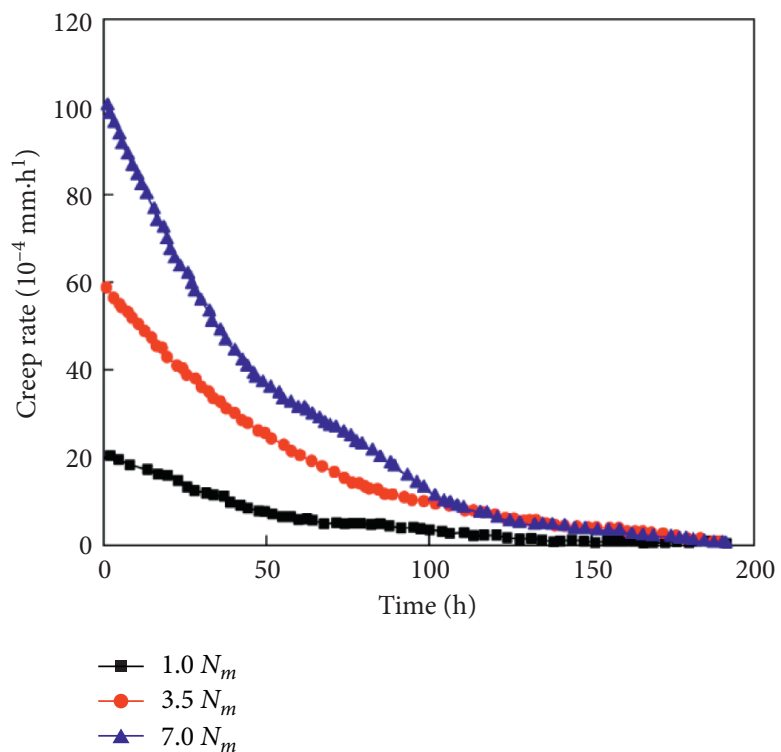

(b)

Figure 16: (a) Deformation and (b) rate of point WCJ6 measured during creep testing.

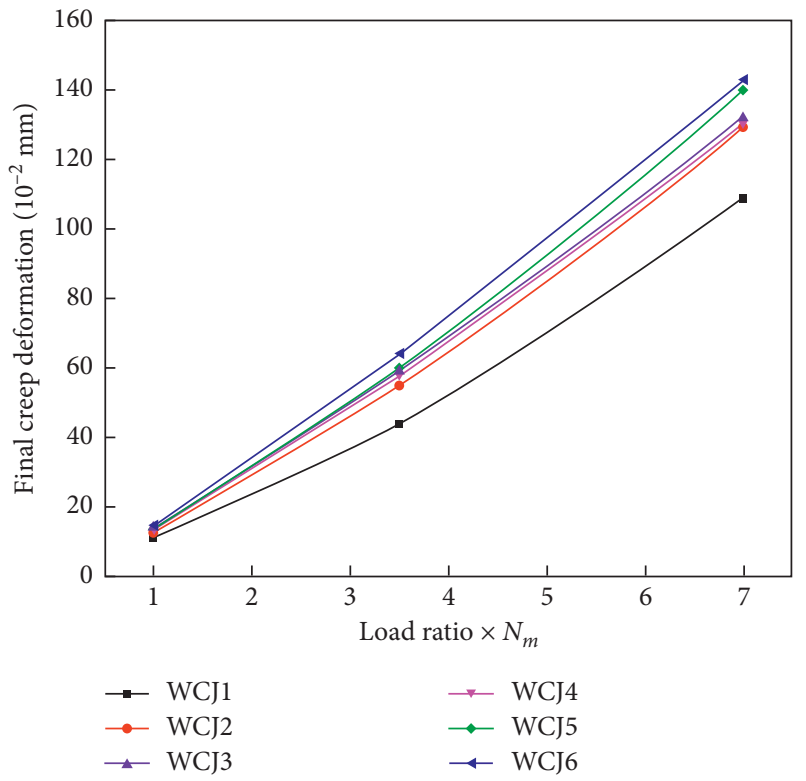

(a)

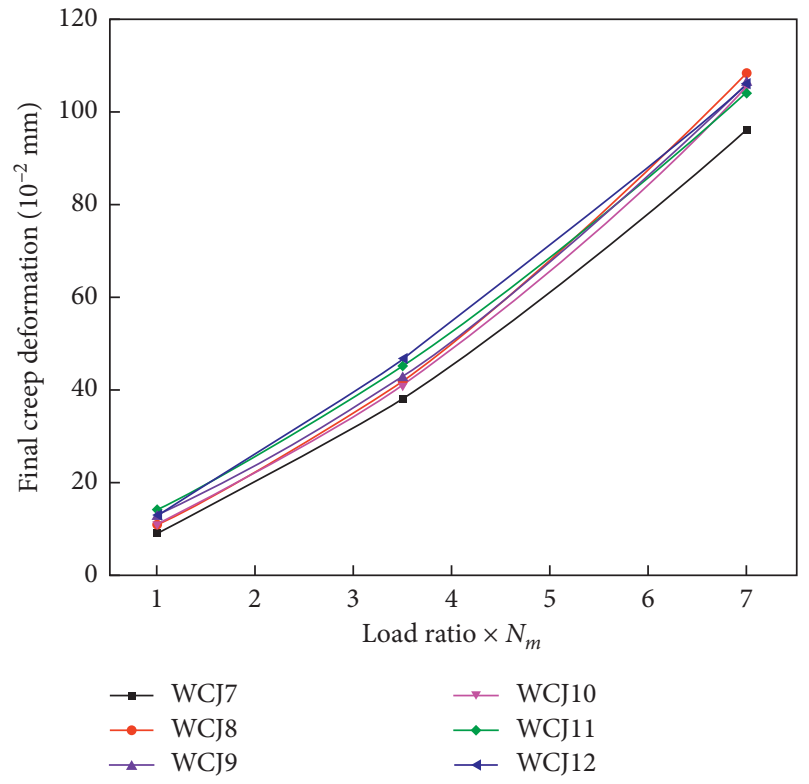

(b)

FIGURE 17: Final creep deformations of interfaces for (a) left anchor and (b) right anchor.

different points. When the load is further increased to $7.0 N_{m}$, the deformations measured at points WCJ1 and WCJ7 are significantly smaller than those measured at other locations while the measurements taken at the remaining points are still close to each other. This feature demonstrates that the creep deformation of the dislocation is minimal at the top section of the front face of the left and right anchors. Such behaviour is consistent with the deformation rule of anchors.

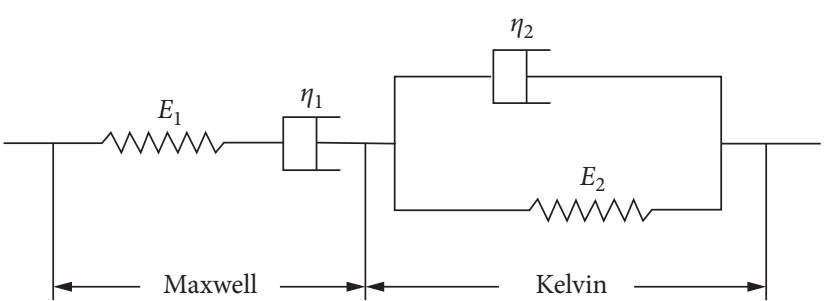

FIgURE 18: Schematic diagram of four-element Burger's model. 


\section{Numerical Calculation}

In order to validate the results of the in situ creep test, a 3D numerical model comprising the left anchor and the surrounding rock was solved on FLAC ${ }^{3 \mathrm{D}}$ platform. In addition, the long-term deformations of the actual full-size tunnel anchors of the Xingkang suspension bridge were evaluated by adopting an empirical method.

4.1. Constitutive Model and Parameters. The in situ testing data show that the surrounding rock exhibits a viscoelastic characteristic when applying the loads of $1.0 \mathrm{~N}_{m}, 3.5 \mathrm{~N}_{m}$ and $7.0 N_{m}$ to the model tunnel anchor. In other words, the creep model should comprise both viscous and elastic elements. In this study, the four-parameter Burger creep model was employed to characterise the aforementioned rheological curve to obtain the corresponding creep parameters. The four-parameter Burger creep model is formed by combining the Kelvin model and Maxwell model [20], as illustrated in Figure 18.

The Kelvin model is suitable for describing the relaxation process under a constant stress condition [21], while the Maxwell model is suitable for describing the creep process under a constant stress condition [22]. In the real situation, an object would undergo both creep and relaxation processes when bearing external forces. The strain generated on a Burger material is equal to the sum of the strains generated from both the relaxation and creep processes; see the following equation:

$$
\varepsilon=\varepsilon_{k}+\varepsilon_{m}
$$

where $\varepsilon_{\mathrm{k}}$ and $\varepsilon_{\mathrm{m}}$ are the strains generated from the Kelvin and Maxwell models, respectively, and $\varepsilon$ is the total strain generated from the Burger creep model.

When the anchor of a suspension bridge is affected by an axial tensile stress $\sigma_{1}$ along the main cable, the deformation of the anchor will induce a radial stress $\sigma_{2}$ on the surrounding rock. The creep constitutive equation of the anchor under the combined effect of $\sigma_{1}$ and $\sigma_{2}$ could be written as follows [23]:

$$
\begin{aligned}
\varepsilon(t)= & \left(\frac{2\left(\sigma_{1}+\sigma_{2}\right)}{9 K_{v}}\right)+\left(\frac{2 \sigma_{1}-3 \sigma_{2}}{9 E_{2}}\right)\left[1-\exp \left(-\left(\frac{E_{2}}{\eta_{2}}\right) t\right)\right] \\
& +\left(\frac{2 \sigma_{1}-3 \sigma_{2}}{9 E_{1}}\right)+\left(\frac{2 \sigma_{1}-3 \sigma_{2}}{\eta_{1}}\right) t,
\end{aligned}
$$

where $K_{\mathrm{v}}$ is the bulk modulus (GPa); $E_{1}$ and $E_{2}$ are the elastic moduli (GPa) used in the Maxwell model and Kelvin model; and $\eta_{1}$ and $\eta_{2}$ are the coefficients of viscosity (GPa.h) used in the Maxwell and Kelvin models.

To examine the relationship between the axial tensile stress $\sigma_{1}$ on the main cable and the radial stress $\sigma_{2}$ on the surrounding rock, the cross section of the anchor is approximately considered as a circle, while the anchor is approximately considered as a wedge body. The direction parallel to the axis of the anchor is set to be the $x$-axis. The radial direction along the cross section of the anchor and perpendicular to the $x$-axis is set as the $r$-axis. The structure and stress condition of the tunnel anchor used in the suspension bridge are given in Figure 19.

Taking any cross section of the anchor, the axial tensile stress could be calculated by

$$
\sigma_{1}=\left(\frac{F}{A}\right)=\left(\frac{F}{\pi r^{2}}\right),
$$

where $F$ is the force applied on the anchor; $A$ is the area of anchor cross section; and $r$ is the radius of anchor cross section.

The axial and radial deformations are calculated by

$$
\begin{aligned}
& \varepsilon_{1}=\left(\frac{\sigma_{1}}{E}\right)=\left(\frac{F}{E \pi r^{2}}\right), \\
& \varepsilon_{2}=\mu \varepsilon_{1}=\left(\frac{\mu \sigma_{1}}{E}\right)=\left(\frac{\mu F}{E \pi r^{2}}\right),
\end{aligned}
$$

where $E$ is the elastic modulus of the anchor concrete, and $\mu$ is the Poisson ratio.

The radial displacement is calculated by

$$
s_{2}=r \varepsilon_{2}=\left(\frac{\mu F}{E \pi r}\right) .
$$

According to the assumption of Winkler's foundation model [24], the axial tension exerted by the surrounding rock on the anchor is expressed as

$$
\sigma_{2}=K s_{2}=\left(\frac{\mu \mathrm{FK}}{E \pi r}\right)=\left(\frac{\mu \mathrm{FK}_{0}}{E \pi r^{2}}\right),
$$

where $K$ is the elastic resistance coefficient of the surrounding rock, and $K_{0}$ is the unit elastic resistance coefficient of the surrounding rock.

When substituting (7)-(11) into (6), we thus obtain the following creep constitutive equation:

$$
\begin{aligned}
\varepsilon(t)= & \left(\frac{F\left(2 E-3 \mu K_{0}\right)}{9 E E_{2} \pi r^{2}}\right)\left[1-\exp \left(-\left(\frac{E_{2}}{\eta_{2}}\right) t\right)\right]+\left(\frac{F\left(2 E-3 \mu K_{0}\right)}{9 E E_{1} \pi r^{2}}\right) \\
& +\left(\frac{F\left(2 E-3 \mu K_{0}\right)}{\eta_{1} E \pi r^{2}}\right) t+\left(\frac{2 F\left(E+\mu K_{0}\right)}{9 E K_{v} \pi r^{2}}\right) .
\end{aligned}
$$

The 3D numerical model comprising the left anchor and the surrounding rock was solved on FLAC ${ }^{3 \mathrm{D}}$ platform. The geometry size of this model is $56.8 \mathrm{~m} \times 20.0 \mathrm{~m} \times 47.2 \mathrm{~m}$, as illustrated in Figure 19. Tetrahedral cells with a side length of $0.5 \mathrm{~m}$ were used to mesh the anchor and the surrounding rock in the model. The remaining region was meshed with tetrahedral cells with a side length of $2 \mathrm{~m}$. There are 37,518 nodes and 216,509 elements in total.

According to the measured results in Figures 9, 12, and 16 , the creep parameters of surrounding rocks were calculated by (12) and are listed in Table 2. When solving the numerical model shown in Figure 19, we used the Mohr-Coulomb criterion to judge the critical yield stress state of the tunnel anchor and surrounding rock. The 


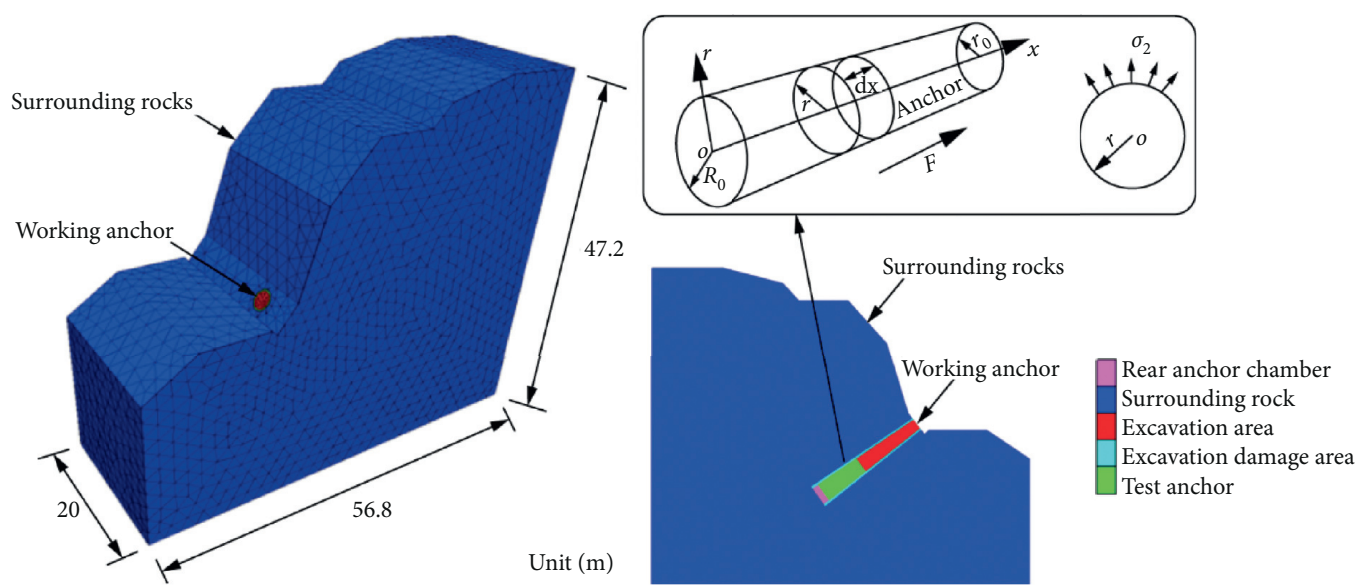

FIGURE 19: 3D calculation model comprised of model anchor and surrounding rock.

TABLE 2: Input parameters of Burger's model used for surrounding rocks.

\begin{tabular}{lcccc}
\hline Load & $E_{1}(\mathrm{GPa})$ & $\eta_{1}(\mathrm{GPa} \cdot \mathrm{h})$ & $E_{2}(\mathrm{GPa})$ & $\eta_{2}(\mathrm{GPa} \cdot \mathrm{h})$ \\
\hline $1.0 N_{\mathrm{m}}$ & 0.44 & 63900 & 5.04 & 20.31 \\
$3.5 N_{\mathrm{m}}$ & 0.23 & 30100 & 3.15 & 10.11 \\
$7.0 N_{\mathrm{m}}$ & 0.15 & 20300 & 1.54 & 4.02 \\
\hline
\end{tabular}

corresponding input parameters are listed in Table 3. According to the test results and safety reservation requirement, the values of $\rho_{0}, \mu_{0}$, and $E_{0}$ are selected from the average values of $\rho, \mu$, and $E ; \sigma_{t 0}, c_{0}$, and $\varphi_{0}$ are selected as 10 , 50 , and 90 percent of $\sigma_{t}, c$, and $\varphi$, respectively. The concrete grade of tunnel anchor is $\mathrm{C} 35$, and its values are referred to at China national standard (GB/T 14902-2012) [25].

In addition, only the gravitational stress field was considered in the calculation, and the normal displacements of the nodes at bottom and sides were constrained. The results obtained from the numerical simulation were compared with the experimental measurements to determine the creep deformation and reveal the creep deformation pattern of the anchor and surrounding rock.

4.2. Parameters for Sensitivity Analysis of Tunnel Anchor Deformation. Sensitivity analysis is conducted to evaluate the effect of parameters used in the Maxwell and Kelvin models on the deformation of tunnel anchor. The parameters for sensitivity analysis of tunnel anchor strain include elastic moduli $E_{1}$ and $E_{2}$ and coefficients of viscosity $\eta_{1}$ and $\eta_{2}$ used in the Maxwell model and Kelvin models. The parameters used for the sensitivity analysis are summarized in Table 4. Assumed elastic moduli $E_{1}$ and $E_{2}$ varying from 0.1 to $0.6 \mathrm{GPa}$ and 1 to 6 are included in this study. The coefficients of viscosity $\eta_{1}$ and $\eta_{2}$ are assumed to be $5 \times 10^{2}$, $1 \times 10^{3}, 5 \times 10^{3}, 1 \times 10^{4}, 5 \times 10^{4}$, and $1 \times 10^{5} \mathrm{GPa} \cdot \mathrm{h}$ and 1,5 , $10,20,50$, and $100 \mathrm{GPa} \cdot \mathrm{h}$, respectively.

4.2.1. $E_{1}$ and $\eta_{1}$ of the Maxwell Model. Figure 20 illustrates the effect of elastic moduli $E_{1}$ on the strain of tunnel anchor under loads of $1.0 \mathrm{~N}_{m}, 3.5 \mathrm{~N}_{m}$, and $7.0 \mathrm{~N}_{m}$. It could be found in Figure 20 that the strains of tunnel anchor increase faster as time goes by and become stable after about $40 \mathrm{~h}$. In addition, the strains decrease with the increase of $E_{1}$ under the three loads. When $E_{1}$ is $0.1 \mathrm{GPa}$, the stable strains under loads of $1.0 N_{m}, 3.5 N_{m}$, and $7.0 N_{m}$ are $65 \times 10^{-5}, 230 \times 10^{-5}$, and $461 \times 10^{-5}$. When $E_{1}$ increase to $0.6 \mathrm{GPa}$, the stable strains under loads of $1.0 \mathrm{~N}_{m}, 3.5 \mathrm{~N}_{m}$, and $7.0 \mathrm{~N}_{m}$ decrease to $19 \times 10^{-5}, 69 \times 10^{-5}$, and $137 \times 10^{-5}$, decreasing by $70.7,70$, and 70.3 percent, respectively. Clearly, the variation of $E_{1}$ would exert significant negative influence on the strain of tunnel anchor, and load would exert positive influence.

Figure 21 illustrates the effect of coefficient of viscosity $\eta_{1}$ on the strain of tunnel anchor under loads of $1.0 \mathrm{~N}_{m}, 3.5 \mathrm{~N}_{m}$, and $7.0 N_{m}$. In Figure 21, the strains of tunnel anchor under loads of $1.0 N_{m}, 3.5 N_{m}$, and $7.0 N_{m}$ increase with time. When the values of $\eta_{1}$ are $5 \times 10^{3}, 1 \times 10^{4}, 5 \times 10^{4}$, and $1 \times 10^{5} \mathrm{GPa} \cdot \mathrm{h}$, the strains become stable after about $50 \mathrm{~h}$. Additionally, the strain of tunnel anchor decreases with the increase of $\eta_{1}$ under the three loads. The maximum decreasing percents under loads of $1.0 \mathrm{~N}_{m}, 3.5 \mathrm{~N}_{m}$, and $7.0 \mathrm{~N}_{m}$ are $35.3,44.3$, and 47.0, respectively. Obviously, $\eta_{1}$ would also exert negative influence on tunnel anchor strain.

4.2.2. $E_{2}$ and $\eta_{2}$ of the Kelvin Model. The effect of elastic moduli $E_{2}$ on the strain of tunnel anchor shows similar trend with that of $E_{1}$. In Figure 22, it could be found that the larger the value of $E_{2}$ is, the smaller the strain of tunnel anchor is. The maximum decreasing percents under loads of $1.0 \mathrm{~N}_{m}$, $3.5 N_{m}$, and $7.0 N_{m}$ are $24.5,21.5$, and 23.5 , respectively.

Figure 23 shows the effect of $\eta_{2}$ on the strain of tunnel anchor under loads of $1.0 \mathrm{~N}_{m}, 3.5 \mathrm{~N}_{m}$, and $7.0 \mathrm{~N}_{m}$. When the value of $\eta_{2}$ is smaller than $20 \mathrm{GPa} \cdot \mathrm{h}$, the strains progressively become stable. The strains of tunnel anchor under the three loads are the first becoming stable when $\eta_{2}$ is $1 \mathrm{GPa} \cdot \mathrm{h}$. Moreover, the coefficient of viscosity $\eta_{2}$ exerts negative influence on the strain of tunnel anchor, and the maximum decreasing percents are $39.1,41.5$, and 39.3 , respectively.

4.3. Calculation Results and Comparative Analysis. After assigning the parameters to the computational model, the numerical simulation was then carried out for at least 
TABLE 3: Input parameters of surrounding rocks and concrete tunnel anchor.

\begin{tabular}{lcccccc}
\hline Position & $\rho_{0}\left(\mathrm{~g} / \mathrm{cm}^{3}\right)$ & $\sigma_{t 0}(\mathrm{MPa})$ & $c_{0}(\mathrm{MPa})$ & $\tan \varphi_{0}$ & $\mu_{0}$ & $E_{0}(\mathrm{GPa})$ \\
\hline Surrounding rock & 2.57 & 0.32 & 0.41 & 0.70 & 0.28 & 2.13 \\
Concrete tunnel anchor & 2.45 & 1.57 & 1.43 & 1.28 & 0.21 & 31.5 \\
\hline
\end{tabular}

TABLE 4: Summary of the parameters used for sensitivity of strain.

\begin{tabular}{|c|c|c|c|c|c|c|}
\hline Elastic moduli $E_{1}(\mathrm{GPa})$ & 0.1 & 0.2 & 0.3 & 0.4 & 0.5 & 0.6 \\
\hline Elastic moduli $E_{2}(\mathrm{GPa})$ & 1 & 2 & 3 & 4 & 5 & 6 \\
\hline Coefficient of viscosity $\eta_{1}(\mathrm{GPa} \cdot \mathrm{h})$ & $5 \times 10^{2}$ & $1 \times 10^{3}$ & $5 \times 10^{3}$ & $1 \times 10^{4}$ & $5 \times 10^{4}$ & $1 \times 10^{5}$ \\
\hline Coefficient of viscosity $\eta_{2}(\mathrm{GPa} \cdot \mathrm{h})$ & 1 & 5 & 10 & 20 & 50 & 100 \\
\hline Load & $1.0 N_{m}$ & $3.5 N_{m}$ & $7.0 N_{m}$ & & & \\
\hline Time (h) & 98 & 168 & 189 & & & \\
\hline
\end{tabular}

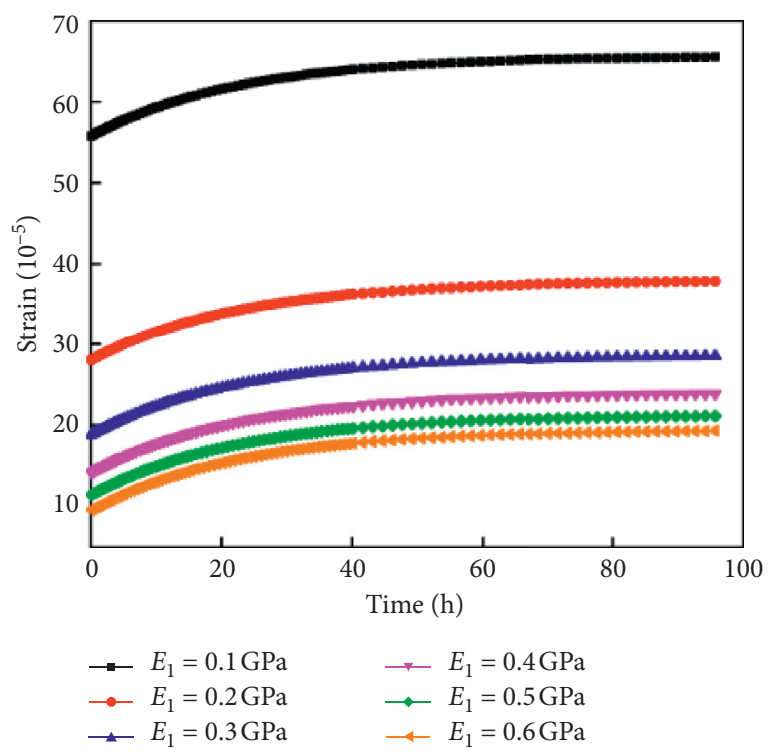

(a)

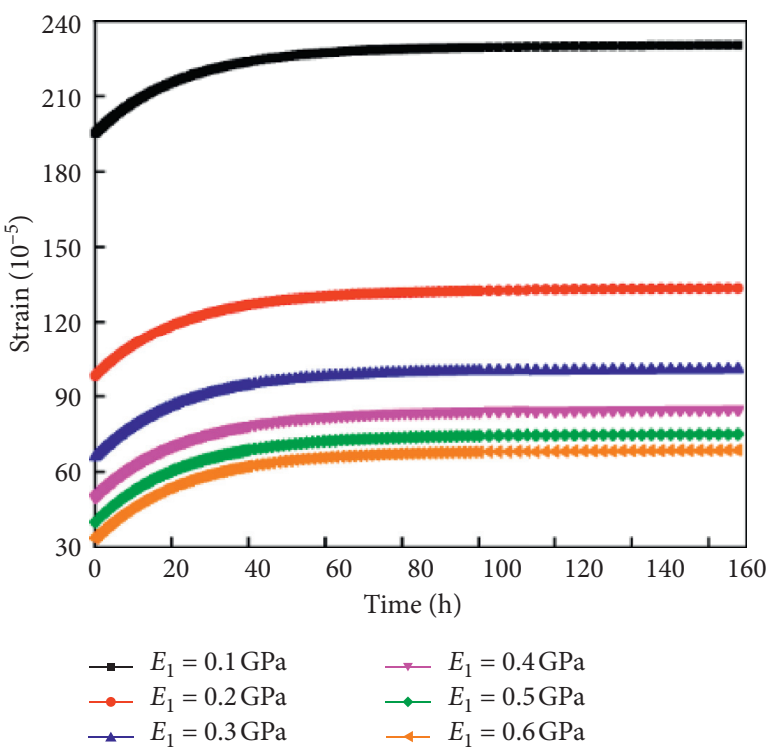

(b)

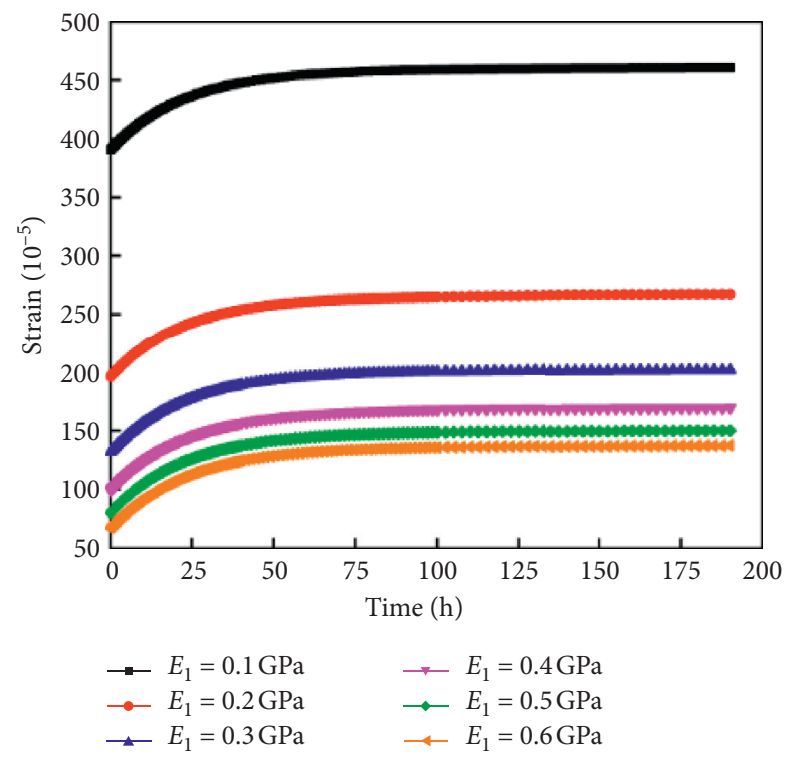

(c)

Figure 20: Effect of $E_{1}$ on the strain of tunnel anchor under loads of (a) $1.0 N_{m}$, (b) $3.5 N_{m}$, and (c) $7.0 N_{m}$. 


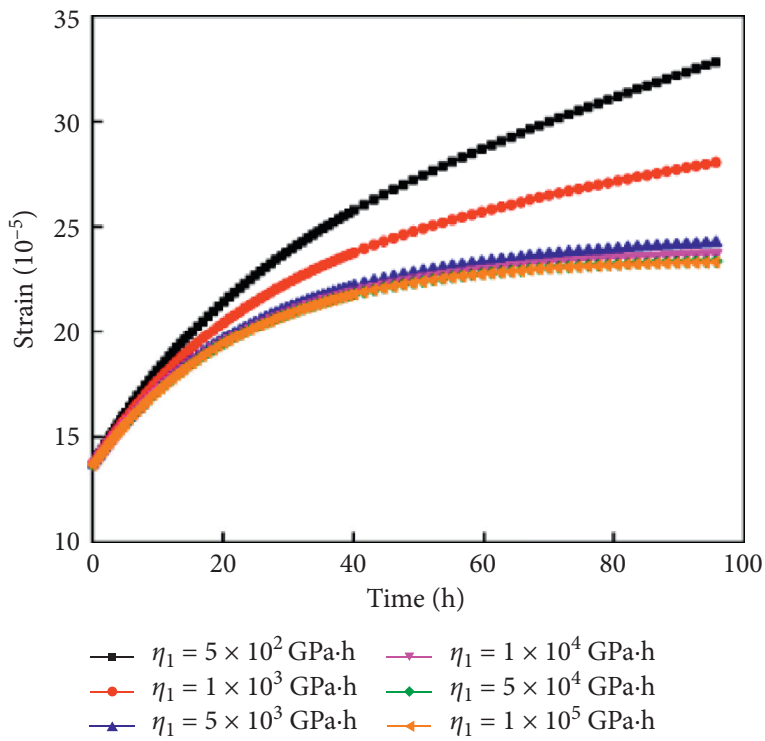

(a)

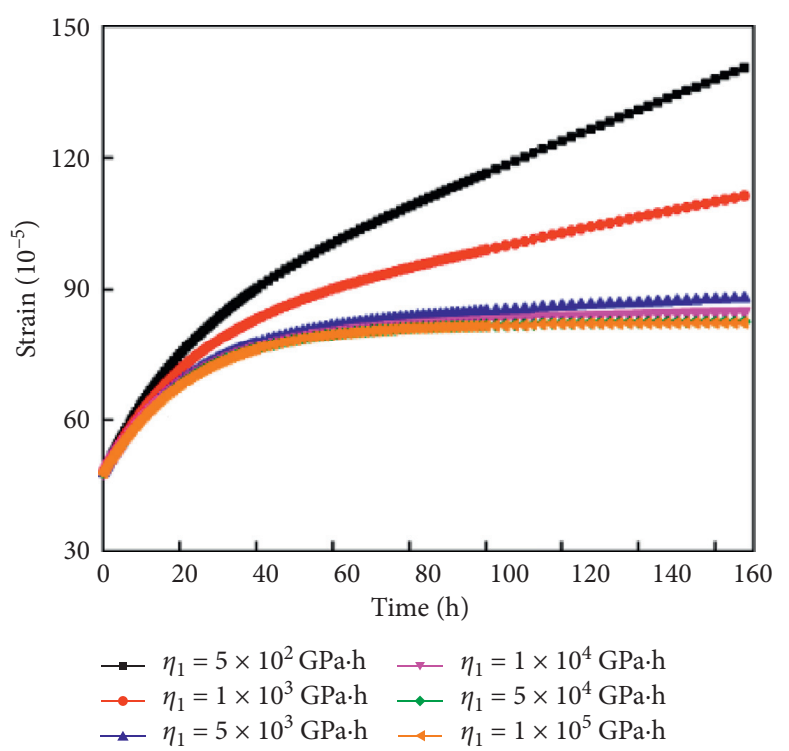

(b)

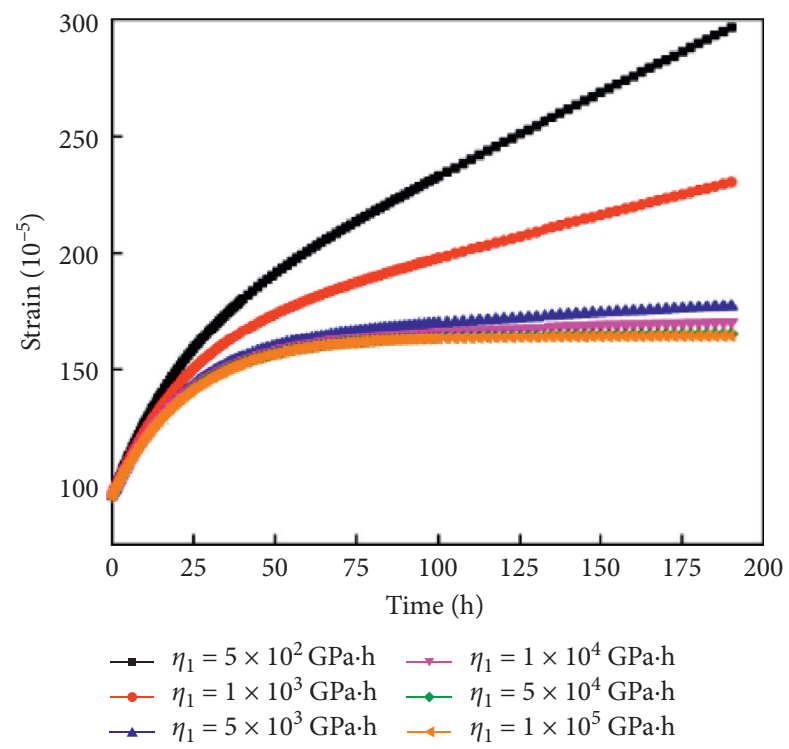

(c)

Figure 21: Effect of $\eta_{1}$ on the strain of tunnel anchor under loads of (a) $1.0 N_{m}$, (b) $3.5 N_{m}$, and (c) $7.0 N_{m}$.

$120 \mathrm{~h}$ under each loading condition. Figure 24(a) exhibits the comparison between the experimental measurements at points of $g_{3}$ and $g_{4}$ in the anchor and the calculation results obtained from FLAC ${ }^{3 \mathrm{D}}$. As shown in Figure 24(a), the relative errors between the calculation values and the experimental measurements are less than $20 \%$ under each loading condition. In particular, there is a minimal difference between the experimental measurements and simulation results of creep deformation at point $g_{3}$ (on the front anchor face) and point $g_{4}$ (on the rear anchor face) under the loads of $1.0 N_{m}$ and $3.5 N_{m}$. When the load was increased to $7.0 N_{m}$, however, the maximum difference between the experimental measurements and simulation results on the front and rear anchor faces reached $0.2779 \mathrm{~mm}$.
Figure 24(b) provides the comparison between the experimental measurements at points of $g_{2}$ and $g_{5}$ in the surrounding rock and the corresponding calculation results. As shown in Figure 24(b), the relative errors between the simulation results and the experimental measurements are less than $25 \%$ under each loading condition. The difference between the experimental measurements and simulation results at measuring point $g_{2}$ is very small under the loads of $1.0 \mathrm{~N}_{m}$ and $3.5 N_{m}$. The maximum difference between the experimental measurements and simulation results at measuring point $g_{5}$ is $0.168 \mathrm{~mm}$. When the load was increased to $7.0 \mathrm{~N}_{m}$, the difference between the experimental measurements and simulation results at measuring point $g_{5}$ became very small. The difference between the experimental measurements and simulation results at measuring point $g_{2}$ is $0.175 \mathrm{~mm}$. 


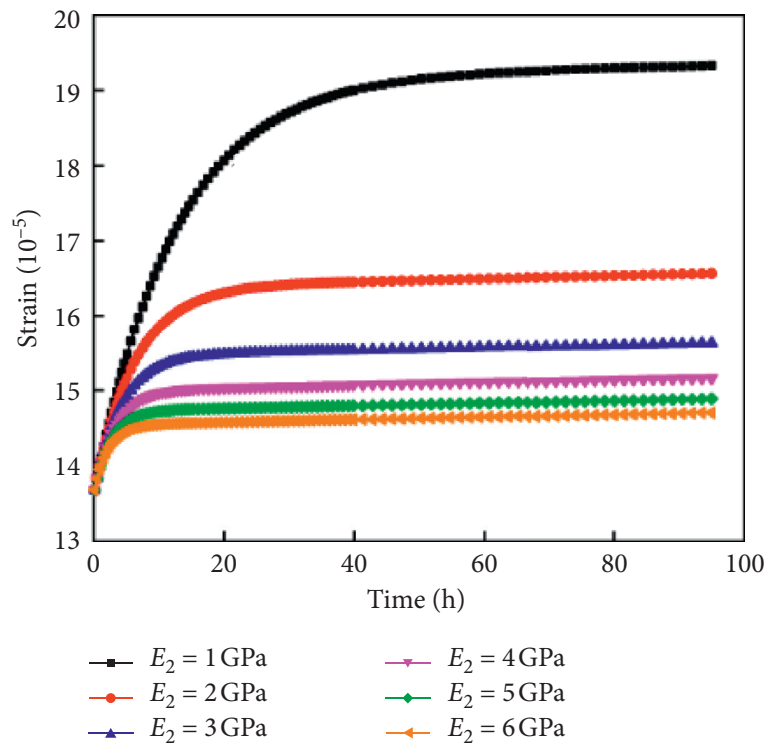

(a)

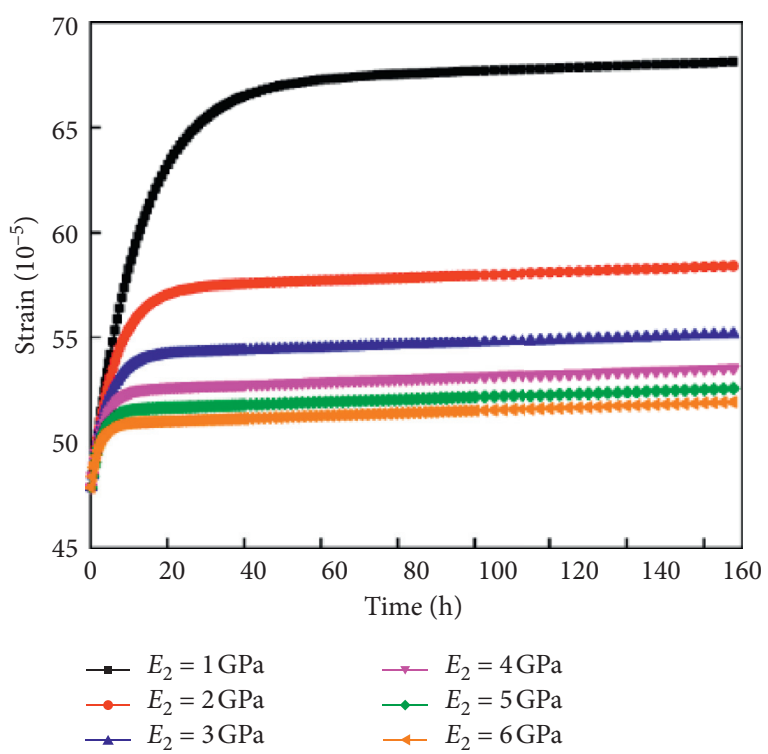

(b)

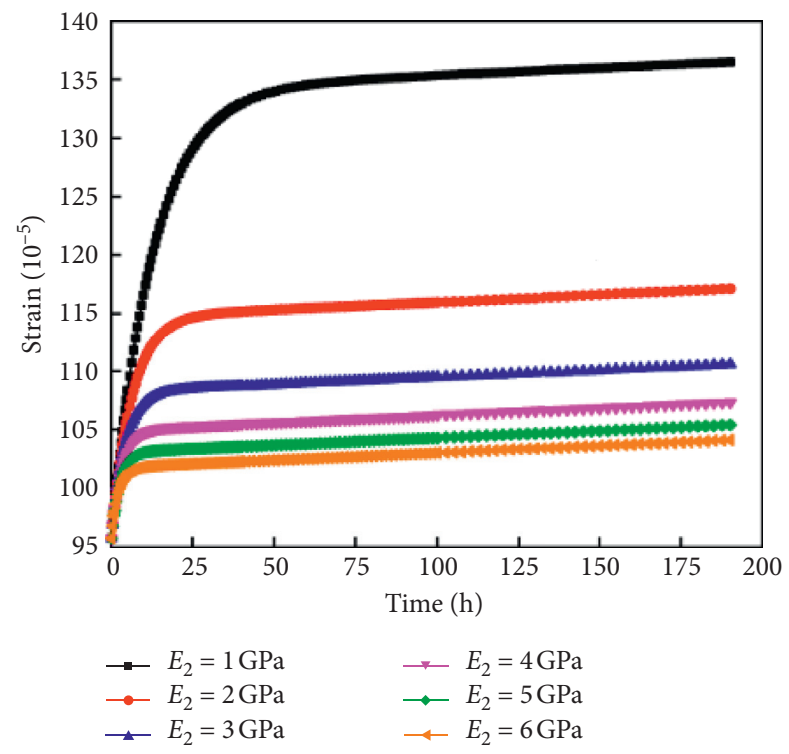

(c)

Figure 22: Effect of $E_{2}$ on the strain of tunnel anchor under loads of (a) $1.0 N_{m}$, (b) $3.5 N_{m}$, and (c) $7.0 N_{m}$.

The above comparisons show that the creep deformation at the measuring points obtained from the numerical calculation shared the same order of magnitude and a similar trend with the experimental measurements. The experimental measurements and simulation results demonstrated the same trend in the change of creep deformation for the anchor and surrounding rock.

4.4. Long-Term Stability of Anchor and Surrounding Rock. Here we further evaluate the long-term creep deformation pattern of the anchor in the suspension bridge and the surrounding rock. We conducted a calculation for the model shown in Figure 19 considering the loading period of 100 years so as to validate if the design of the anchor satisfies the requirements of the specification. Each loading period is taken to be 10 years. We only analyse the creep behaviours at two measuring points on the front and rear faces of the anchor $\left(g_{3}\right.$ and $\left.g_{4}\right)$ and two other measuring points on the surrounding rock $\left(g_{2}\right.$ and $\left.g_{5}\right)$. The calculation results revealed the creep deformation pattern of the anchor and the surrounding rock under a normal design load over a total duration of 100 years (Figure 25).

It could be seen from Figure 25 that there is only a slight difference between the creep deformations at measuring points $g_{2}$ and $g_{5}$ on the surrounding rock over the duration of 100 years. In addition, these creep deformations barely changed with increasing time, and the results indicate a stable creep behaviour. Moreover, while the creep deformations at points $g_{3}$ and $g_{4}$ on the anchor differ slightly 


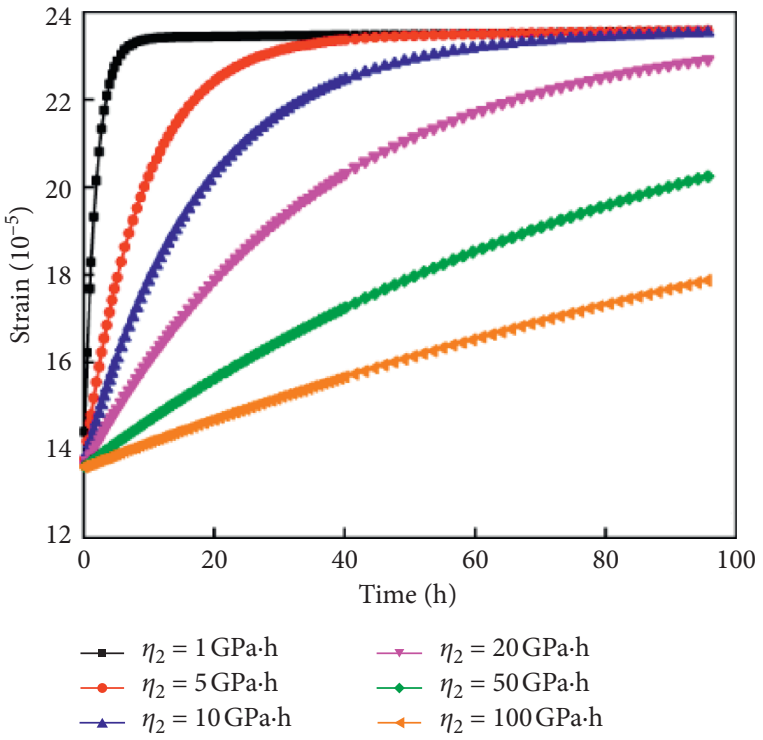

(a)

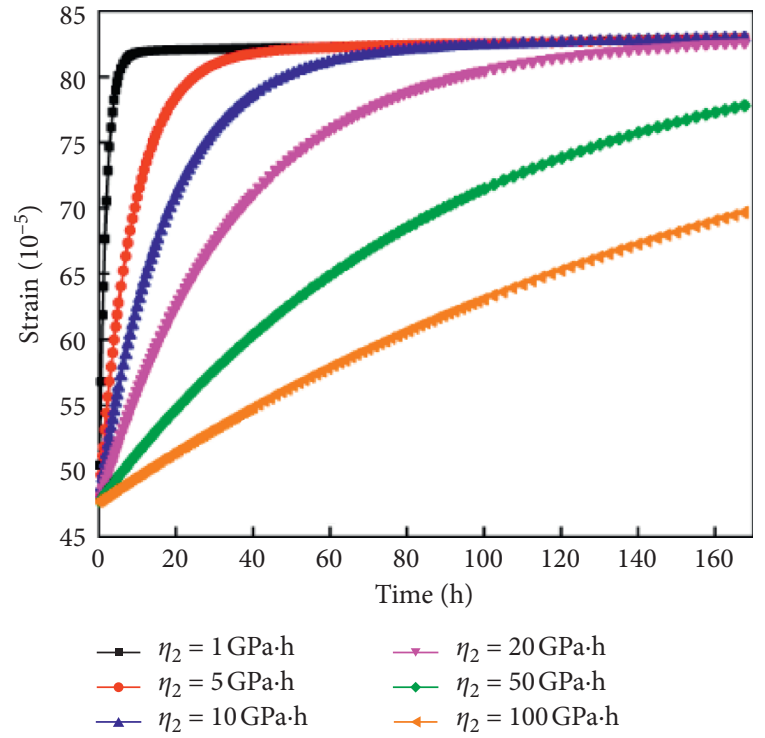

(b)

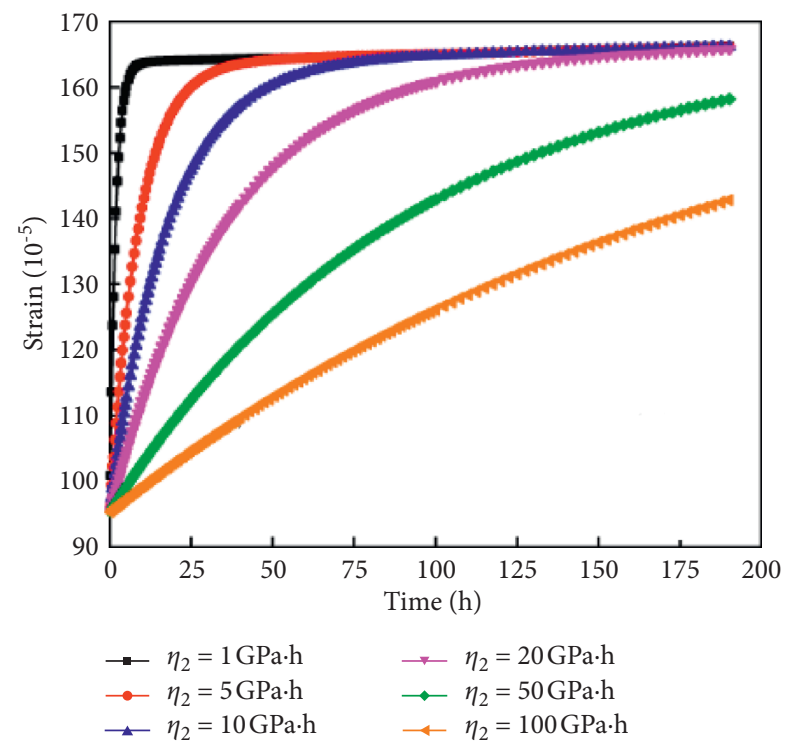

(c)

FiguRE 23: Effect of $\eta_{2}$ on the strain of tunnel anchor under loads of (a) $1.0 N_{m}$, (b) $3.5 N_{m}$, and (c) $7.0 N_{m}$.

from each other, both of these values increase at a constant rate over time. The maximum creep deformation of the anchor in the suspension bridge reached $1.377 \mathrm{~cm}$ over the duration of 100 years.

The Honshu-Shikoku Bridge Authority in Japan reported the calculation of allowable horizontal displacement for anchors used in ultralong suspension bridges (1000 to $1500 \mathrm{~m}$ long) [26], and the empirical equation is given by

$$
\delta=0.017 L
$$

where $\delta$ is the allowable horizontal displacement $(\mathrm{cm})$ and $L$ is the main span of the bridge $(\mathrm{m})$.

The main span length of Xingkang Bridge is $1100 \mathrm{~m}$. According to (13), the maximum allowable horizontal displacement of the real working anchor is $18.7 \mathrm{~cm}$. Therefore, the maximum allowable horizontal displacement of the scaled anchor model is $1.87 \mathrm{~cm}$. Such a value is greater than the maximum creep deformation of $1.377 \mathrm{~cm}$ for the anchor in the suspension bridge over the duration of 100 years. Therefore, the creep behaviour of the anchor satisfies the requirement of the specification and could be categorised as a stable creep phenomenon.

Clearly, the creep deformation of the anchor along the tensile direction increases with increasing level of load from $1.0 N_{m}$ to $7.0 N_{m}$. In addition, with increasing load level, the creep deformations measured at the points with maximum stress in the anchor, surrounding rock, and the interface tend to be stable eventually after a decelerating growth period. This phenomenon indicates that the real working 


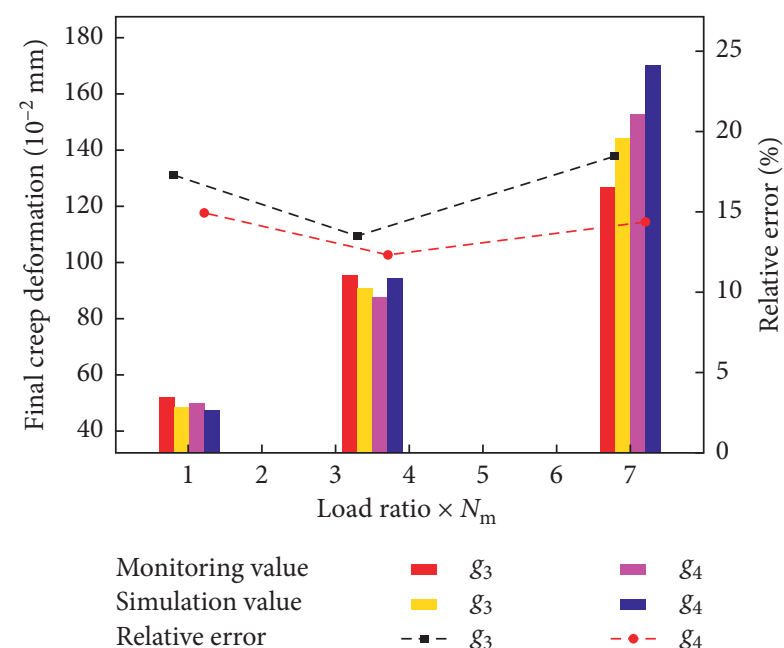

(a)

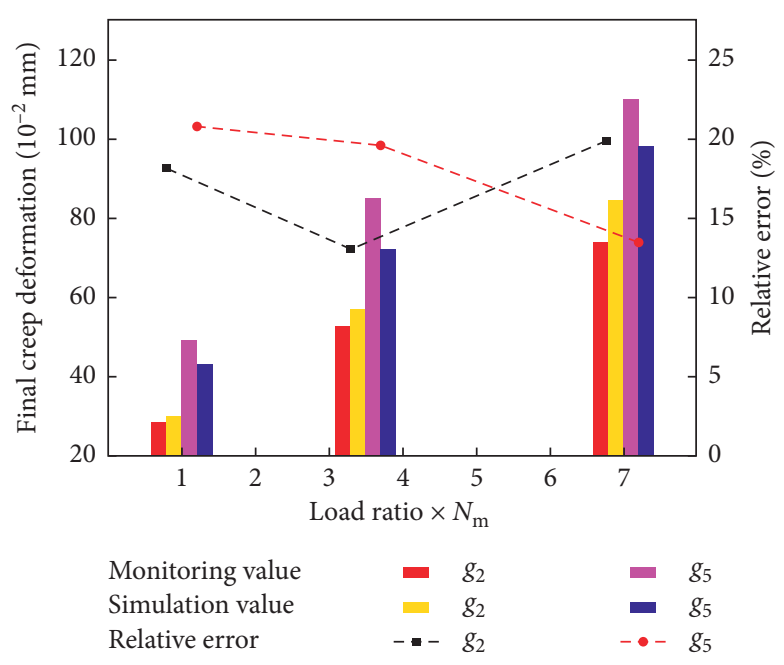

(b)

Figure 24: Comparison between experiment measurements and simulation results of (a) tunnel anchor and (b) surrounding rocks.

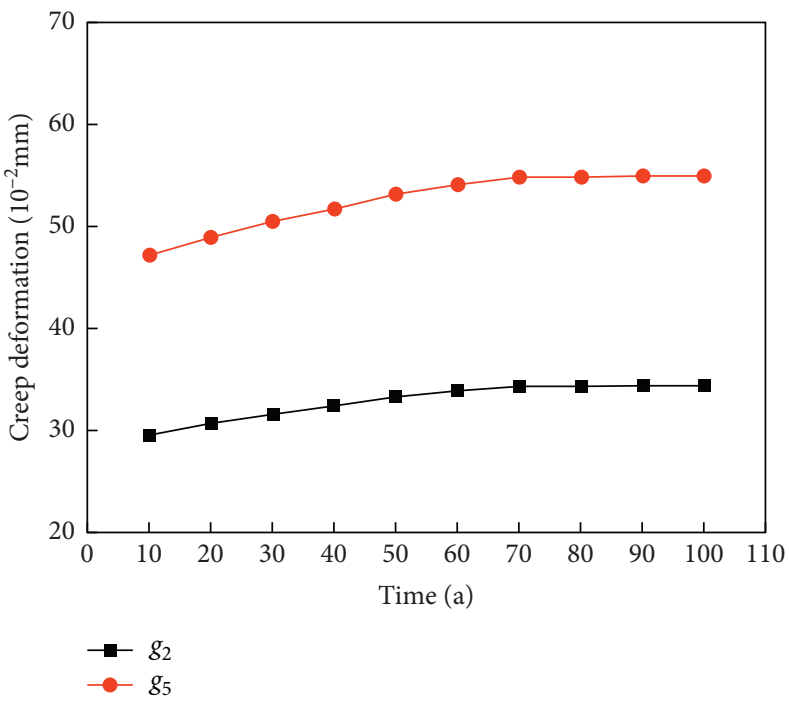

(a)

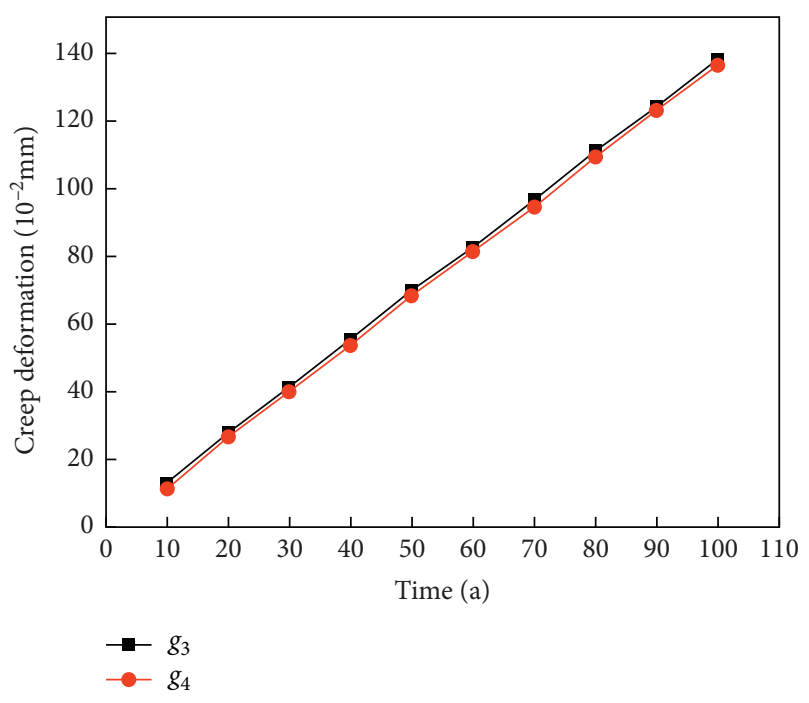

(b)

FIGURE 25: Long-term creep patterns of (a) surrounding rock and (b) real working anchor.

tunnel anchor would undergo a stable creep behaviour under different load levels. Since the creep deformation of the anchor does not exceed the maximum allowable value under the normal design load, the Xingkang Bridge would be in a long-term safe running state.

\section{Conclusions}

(1) The creep deformations measured at the front and rear faces of the anchor were consistent with each other. The average creep deformations of anchors were $0.54 \mathrm{~mm}, 0.90 \mathrm{~mm}$, and $1.39 \mathrm{~mm}$ under loads of $1.0 N_{m}, 3.5 N_{m}$, and $7.0 N_{m}$, respectively. The left and right anchors shared a similar creep deformation.

(2) The region between the left and right anchors experienced the largest creep deformations of $0.49 \mathrm{~mm}$,
$0.85 \mathrm{~mm}$, and $1.10 \mathrm{~mm}$ under the three loading conditions, respectively. The creep deformation became larger as it got closer to the anchor. Under the loads of $1.0 \mathrm{~N}_{m}$ and $3.5 \mathrm{~N}_{m}$, the creep deformation along the vertical direction was greater than that along the tensile direction. When the load was increased to $7.0 N_{m}$, however, the creep deformation along the tensile direction became slightly larger than that along the vertical direction.

(3) The maximum creep deformation was measured at point WCJ6 located on the interface between the bottom plate of the left anchor and the surrounding rock. The maximum creep deformations of the interface between anchor and surrounding rock were $0.15 \mathrm{~mm}, 0.64 \mathrm{~mm}$, and $1.43 \mathrm{~mm}$, respectively, under the three loading conditions. The difference between 
the creep deformations measured at different points on the interface between anchor and surrounding rock became more significant with increasing load.

(4) Numerical analysis shows that the creep deformation of anchor and surrounding rock shared the same order of magnitude and a similar trend with the experimental measurements. The locations with maximum stress in the anchor, the surrounding rock, and the interface experienced a creep deceleration stage.

(5) Only one type of concrete model anchor with one size (i.e., front face is $1.48 \mathrm{~m} \times 1.56 \mathrm{~m}$, rear face is $1.77 \mathrm{~m} \times 1.90 \mathrm{~m}$, and length is $4.00 \mathrm{~m}$ ) and one type of rock (i.e., altered adamellite) is taken into consideration in this work. Hence, the presented results are applicable to limited cases, but the presented results merit close attention as a valuable source of reference in engineering projects with similar conditions.

\section{Data Availability}

The data used to support the findings of this study are included within the article.

\section{Conflicts of Interest}

The authors declare that there are no conflicts of interest regarding the publication of this paper.

\section{Acknowledgments}

The authors thank Elsevier's Webshop for editing and polishing this paper. This work was supported by the Key Research Project of Sichuan Province (Grant no. 20ZDYF1468)

\section{References}

[1] V. Kulbach and I. Talvik, "Analysis of a self-anchored suspension bridge in Estonia," IABSE Symposium Report, vol. 84, no. 9, pp. 86-93, 2001.

[2] L. Y. Luo and J. Wei, "Effect of rock mass creep on stability of anchorage surrounding rock of suspension bridge tunnel," Highway Engineering, vol. 32, no. 3, pp. 133-136, 2007, in Chinese.

[3] I. Venanzi, R. Castellani, L. Ierimonti, and F. Ubertini, "An automated procedure for assessing local reliability index and life-cycle cost of alternative girder bridge design solutions," Advances in Civil Engineering, vol. 2019, Article ID 5152031, 17 pages, 2019.

[4] A. S. Nowak and T. Cho, "Prediction of the combination of failure modes for an arch bridge system," Journal of Constructional Steel Research, vol. 63, no. 12, pp. 1561-1569, 2007.

[5] T. J. Matarazzo, P. Santi, S. N. Pakzad et al., "Crowdsensing framework for monitoring bridge vibrations using moving smartphones," Proceedings of the IEEE, vol. 106, no. 4, pp. 577-593, 2018.

[6] C. Liu, S. Zhang, E. Hao et al., "Joint earthquake, wave and current action on the pile group cable-stayed bridge tower foundation: an experimental study," Applied Ocean Research, vol. 63, pp. 157-169, 2017.

[7] Y. Han, X. Liu, D. Li et al., "Model test on the bearing behaviors of the tunnel-type anchorage in soft rock with underlying weak interlayers," Bulletin of Engineering Geology and the Environment, vol. 79, no. 2, pp. 1023-1040, 2020.

[8] Q.-H. Zhang, Y.-J. Li, M.-W. Yu, H.-H. Hu, and J.-H. Hu, "Study of the rock foundation stability of the Aizhai suspension bridge over a deep canyon area in China," Engineering Geology, vol. 198, pp. 65-77, 2015.

[9] J. Cao, X. Y. Wang, H. X. Zuo, H. M. Liu, and W. W. Zheng, "Theoretical and experimental research on load transfer of anchorage stress in soil anchor," Advanced Materials Research, vol. 859, pp. 309-314, 2013.

[10] D. Huang, J. J. Yao, and H. Wang, "Design of tunnel anchors for suspension bridges in mountainous highways," Bridge Construction, vol. 3, pp. 47-50, 2010, (in Chinese).

[11] H. J. Wu and W. L. Qiu, "Numerical simulation and calculation analysis of suspension bridge anchorage system," Advanced Materials Research, vol. 446-449, pp. 1042-1045, 2012.

[12] D. Griggs, "Creep of rocks," The Journal of Geology, vol. 47, no. 3, pp. 225-251, 1939.

[13] E. Maranini and M. Brignoli, "Creep behaviour of a weak rock: experimental characterization," International Journal of Rock Mechanics and Mining Sciences, vol. 36, no. 1, pp. 127-138, 1999.

[14] Y. Li and C. Xia, "Time-dependent tests on intact rocks in uniaxial compression," International Journal of Rock Mechanics and Mining Sciences, vol. 37, no. 3, pp. 467-475, 2000.

[15] Z. Tomanovic, "Rheological model of soft rock creep based on the tests on marl," Mechanics of Time-dependent Materials, vol. 10, no. 2, pp. 135-154, 2006.

[16] W. Chen, F. Wang, M. Feng et al., "Study of a modified nonunified model for time-dependent behavior of metal materials," Mechanics of Materials, vol. 113, pp. 69-76, 2017.

[17] Y. Yi, W. Zhou, G. Ma et al., "Rheological study of granular materials based on exact scaling," Geomechanics, vol. 37, no. 6, pp. 1799-1808, 2016, (in Chinese).

[18] C. Yang, D. Huang, R. Cai et al., "Triaxial unloading creep tests on rock mass with an open and penetrating flaw," Geotechnical Mechanics, vol. 39, no. 1, pp. 53-62, 2018, (In Chinese).

[19] M. Lei, L. Peng, and C. Shi, "Model test to investigate the failure mechanisms and lining stress characteristics of shallow buried tunnels under unsymmetrical loading," Tunnelling and Underground Space Technology, vol. 46, pp. 64-75, 2015.

[20] A. S. Okuka and D. Zorica, "Fractional Burgers models in creep and stress relaxation tests," Applied Mathematical Modelling, vol. 77, pp. 1894-1935, 2020.

[21] G. Sciumè, F. Benboudjema, C. De Sa, F. Pesavento, Y. Berthaud, and B. A. Schrefler, "A multiphysics model for concrete at early age applied to repairs problems," Engineering Structures, vol. 57, pp. 374-387, 2013.

[22] T. A. Alabed, O. M. Abuzeid, M. Barghash et al., "A linear viscoelastic relaxation-contact model of a flat fractal surface: a Maxwell-type medium," The International Journal of Advanced Manufacturing Technology, vol. 39, no. 5-6, pp. 423430, 2008.

[23] Z. P. Zhang, P. F. Gou, S. J. Wei et al., "Experimental study on creep performance of anchoring body," Railway Engineering, vol. 4, pp. 126-129, 2009, (in Chinese).

[24] L. Z. Wu and R. Q. Huang, "Calculation of the internal forces and numerical simulation of the anchor frame beam 
strengthening expansive soil slope," Geotechnical and Geological Engineering, vol. 26, no. 5, pp. 493-502, 2008.

[25] Bureau of China Standards (BCS), Ready-mixed Concrete, Bureau of China Standards (BCS), Beijing, China, 2012, (in Chinese).

[26] D. M. Frangopol and K. Imai, "Reliability of long span bridges based on design experience with the Honshu-Shikoku bridges," Journal of Constructional Steel Research, vol. 60, no. 3-5, pp. 373-392, 2004. 